\title{
Historicismo, sujeto y moral \\ (Max Weber y el «mito de la transparencia de la razón»)
}

\author{
ANTONIO VALDECANTOS \\ Instituto de Filosofía, CSIC
}

Recurso frecuente de lo que hoy reconstruimos como Ilustración fue desarbolar supersticiones y mitos. Es, sin embargo, Iugar común redargüir que quien derriba ídolos no está libre de edificar otros nuevos (ni -tópico éste que cunde por doquier- de convertir su gesto iconoclasta en mito fundacional). No menos acostumbrado es apuntar a Max Weber como al primer desvelador de algún que otro episodio sobresaliente de la historia de la razón ilustrada, ya sea para abundar en su diagnóstico, ya para intentar salir de lo que se tiene por su "círculo hechizadon. En lo que sigue, se trata de rastrear algunas de las claves configuradoras de la crítica weberiana de la cultura procurando retrotraer a su desmantelamiento metodológico del ideal historicista, los términos en que elabora su problematización del sujeto mo- derno. La inversión semántica de las categorías centrales de la epistemología y la Weltanschautung del historicismo alemán decimonónico permite a Max Weber descubrir patologías del paradigma ilustrado allí donde se suele situar un momento de crítica del mismo. Siguiendo los pasos de esta estrategia weberiana, nos es posible reconstruir la noción hipostasiada de racionalidad y de sujeto que Weber parece denunciar como tentación dogmática de la razón ilustrada. El programa weberiano constituye así el desenmascaramiento de un relato complaciente de lo moderno -al que llamo el «mito de la transparencia de la razón”y sobre ese supuesto cabe releer sus propuestas éticas más controvertidas, en particular la distinción entre «ética de convicción» y uética de responsabilidad".

De la razón y del sujeto se ha hecho usual predicar parejos males. Es corriente que se quiera ver en las patologías de una el más seguro indicio de las del otro, sin que importe mucho por dónde empezar el diagnóstico. Pero cualquier lectura de la historia de la razón moderna, más que una robusta identidad, lo que arroja es una yuxtaposición algo desordenada de modos de ejercer esa facultad que se tiene por bandera suya. El libertino, el sabio ascético, el maximizador de beneficios, el artista iconoclasta, el revolucionario, el tecnócrata, el provocador cultural, el moralista y el cínico son tipos humanos que con parecido derecho pueden reivindicar para sí la condición de usuarios de la razón ilustrada -y aun de hijos legítimos suyos-, sin que quepa establecer un orden de primogenitura libre de expresar un parti pris disputable. Cada una de las 
encarnaciones prototípicas de la subjetividad ilustrada cuenta en su haber con un caudal de "razones" dudosamente composibles unas con otras. Interrogarse con fruto por lo que esconde el término "razón» habría de equivaler en definitiva a distinguir entre los varios usos - no necesariamente compatibles - que acertemos a considerar los más característicos suyos y a tratar de definir aquello que, a pesar de todo, hace que tenga sentido examinarlos en su conjunto. La acuñación del barbarismo Rationalität expresó en lengua alemana la oportunidad de semejante estrategia diseccionadora y analítica en el examen de la razón contemporánea. ${ }^{1}$ Cuando hablamos de «racionalidad» nos las habemos siempre con un referente plural, como si sospecháramos que el único tribunal de la razón a que cabe acudir no acostumbra a emitir veredictos por unanimidad y que, desde luego, ningún litigante se somete a él como a instancia inapelable.

Suele situarse un episodio crucial de la historia del vocablo "racionalidad» en la obra de Max Weber. "Racionalidad», «racionalismo» o "racionalización" son tếrminos cuya historia habría sido muy otra si Weber no los hubiera sometido a «un uso tan complejo, pluridimensional y polisémico" como el que hoy puede con justicia atribuírsele. ${ }^{2}$ "Opaco y movedizo sin remisión posible», ${ }^{3}$ el concepto weberiano de racionalidad (o, en rigor, los distintos conceptos que en él se entrecruzan) ha proyectado sin cesar su sombra sobre más de un intento piadoso por rehabilitar lo que alguien ha llamado «la Razón con mayúscula». ${ }^{4} \mathrm{La}$ concepción weberiana ha proporcionado a la filosofía y la teoría social del siglo XX el vocabulario con el que aún se juzga sobre la racionalidad de las acciones, de las instituciones, de los valores o de la historia. Después de Weber, sabemos mejor que debajo del término "razón" no habita la armonía, y que ni mucho menos todo aquello que podemos estar dispuestos a reputar racional lo afirmaremos al mismo tiempo como deseable.

No ha faltado quien haya atribuido a Weber análogo papel en la historia del sujeto modemo. Al igual que cualquier noción enfática de razón queda disuelta en el análisis weberiano de las formas de racionalidad, la teoría de la acción de Weber habría acabado, al término de una "crisis de larga duración del sujeto", con la relación individuo-sociedad como estructura constituyente del vínculo social. ${ }^{5}$ Con ello no se haría, segín Marramao, sino extraer las consecuencias de lo que ya habían preconizado en otros registros Berkeley, Hume y Nietzsche: el fin del sujeto como «núcleo originario y estable de autoconsciencia, centro compacto y homogéneo de la identidad y substrato permanente de las sensaciones". 6 Resulta difícil disentir de Marramao en su visión del programa científico de Max Weber como una pluriforme tematización de la crisis de la subjetividad moderna, si bien no es ocioso, aun aceptando las 
líneas generales de su esquema, tratar de señalar con algo más de detalle qué jalones de la referida "crisis de onda larga" son aquellos en que se contextualizan los teoremas weberianos. En lo que sigue, trataré de mostrar la manera como en la obra metodológica de Max Weber se halla presente la crítica sistemática de un ideal de subjetividad plenamente representativo de la crisis de la razón ilustrada. Se trata de la noción de sujeto característica de la autocomprensión metodológica de las «ciencias del espíritu" y de la visión historicista del mundo.

Desde esta perspectiva, la obra "metodológica" de Max Weber desborda los límites del marco polémico que le sirve de contexto. En los ensayos gnoseológicos weberianos confesadamente coyunturales y de forma y contenido a menudo fragmentarios - ${ }^{7}$ aparece como motivo recurrente la crítica, junto con aspectos internos al método de la ciencia histórica y económica, de la noción de subjetividad que la visión historicista del mundo presupone. Al hilo de las críticas a Roscher, Gottl, Knies, Münsterberg, Lipps, Simmel, Ostwald o Meyer puede descubrirse la forma como Weber se enfrenta a toda una visión del mundo de la que extrae los rasgos definitorios de un ideal de sujeto heredero de las antinomias de la racionalidad ilustrada. El desmantelamiento de la noción historicista de subjetividad es un buen hilo conductor con el que guiarse por el territorio - a menudo selvático- de las críticas weberianas a la metodología historicista. Si, para Weber, el patrón epistemológico historicista es recusable, ello se debe en sustancia a que incorpora un modelo de subjetividad y de acción inútil para comprender la lógica de la racionalización con que se define lo moderno. La consciencia weberiana de la época oficia como motor de la metodología, y cualquier instrumento conceptual que satisfaga ese interés último de la investigación habrá de proporcionar una noción del agente social apta para entender aquello que hace de la subjetividad postilustrada un episodio rigurosamente novedoso en la historia del sujeto.

Personalidad es el nombre del sujeto en la semántica historicista. También lo es, como algún autor ha dejado claro, en el vocabulario weberiano. ${ }^{8}$ Pero la construcción historicista del sujeto pasa por una hipóstasis de la personalidad, herencia devaluada del clasicismo y del romanticismo, y, primera y fundamentalmente, el desenmascaramiento weberiano de la ilusión de la personalidad adopta la forma de la crítica epistemológica. No podría ser de otro modo, si se tiene en cuenta que el viejo concepto de personalidad total sobrevive fosilizado en las ciencias del espíritu (de las que constituye una categoría omnipresente) y, muy en particular, en la autocomprensión metodológica de las mismas. El rasgo que hace de la aportación weberiana al Methodenstreit algo más que una toma de partido estrictamente epistemológica es la manera como logra articular las categorías centrales de la metodología historicis- 
ta —en particular las de "personalidad", "vivencia» y "causalidad por libertad»- en un esquema global que permite descubrir tras ellas un integrado modelo de subjetividad. Pero, además, las críticas de Weber a los metodólogos de las ciencias del espíritu permiten descubrir en la epistemología historicista supuestos y consecuencias no expresados por la misma. Al incorporar elementos no metodológicos, la reconstrucción weberiana de la noción historicista de subjetividad arroja luz sobre la manera como epistemología y visión del mundo se articulan en el historicismo. La metodología de las ciencias del espíritu - parece pensar Max Weber- es el lenguaje en que se expresa la construcción postilustrada de la subjetividad, y el cuestionamiento de la lógica de la segunda ha de llevarse a cabo desenredando los equívocos del lenguaje de la primera.

El examen de los usos de la noción de "personalidad" es una constante de la crítica epistemológica de Weber. El ideal metodológico de las ciencias del espíritu se cifraba en una descripción de lo individual, entendido como lo irrepetible e irreductible a determinación nomológica. Sólo lo individual es real (wirklich), y captarlo en su especificidad es la tarea de una correlativa "ciencia de la realidad" (Wirklichkeitswissenschaft). Con un máximo de comprensión y un mínimo de extensión en el sentido de la lógica tradicional, los conceptos de una ciencia tal - a diferencia de los de las "ciencias de leyes» (Gesetzeswissenschaften) - habrían de posibilitar el descubrimiento de los rasgos característicos de las individualidades objeto de interés (aun a sabiendas de la imposibilidad de un nivel último de análisis: individuum est ine(fabile). La individualidad de la que las «ciencias de realidad" se pretenden conocedoras no es en exclusiva el individuo humano. Para Weber, que sigue en esto a Rickert, el ámbito de competencia de las ciencias de realidad se sitúa:

alli donde lo esencial, es decir, aquello que de los fenómenos es para nosotros digno de ser conocido, no se agota con su clasificación (Einordnung) en un concepto de género; alli donde es la concreta realidad como tal (die konkrete Wirklichkeit als solche) lo que nos interesa.'

El objeto de las Wirklichkeitswissenschaften es cualquier efectivo fragmento de realidad en el que se manifiesten las propiedades típicas del individuo: acontecimientos y procesos, colectividades e instituciones, textos y documentos son «individualidades históricas» de pleno derecho. El modelo metodológico de las "ciencias de realidad" aspira a una descripción completa de lo específico de la individualidad histórica, y, si bien este ideal se proclama de aplicabilidad irrestricta ( $\sin$ que las ciencias de la naturaleza hayan de quedar necesariamente excluidas del mismo), el paradigma de la individualidad histórica es el sujeto humano en cuanto actor de la historia. En la epopeya historicista, la realidad es la obra de 
las grandes individualidades - trasuntos del genio y el héroe de otro tiempo-, y la adecuada comprensión de los hechos culturales es una con la captación de lo específico de sus actores. ${ }^{10}$

Pero el ideal historicista de personalidad no sólo se alimenta de lo que las ciencias del espíritu definen como su objeto paradigmático. Es conocido cómo la reflexión metodológica historicista formula esquemas cognoscitivos que pretenden hacer operativa alguna forma de inmediata comunión del objeto de conocimiento - por antonomasia la Persönlichkeit excelente captada en su plenitud y especificidad-con el sujeto del mismo. Si la individualidad histórica deviene cognoscible, ello le ocurre por ser depositaria de rasgos que potencialmente pertenecen también al sujeto cognoscitivo. Lo que cl devenir hístórico encierra es un caudal de "vivencias" (Erlebnisse) de personalidades individuales que se ofrecen a la "comprensión simpatética» (Einfühlung) del investigador de las ciencias de la cultura y, para este último, la forma de la comprensión (Verstehen) consiste en "revivir» (nacherleben) las vivencias de la personalidad a cuyo estudio se consagra. Gracias a una tal reproducción de la totalidad de los motivos, intenciones y perspectivas del agente histórico por la capacidad de penetración del estudioso, le será dado a éste reconstruir la trama de la realidad histórica, y ello de manera inmediata y realista, sin los esquematismos y abstracciones con que las «ciencias de leyes» están determinadas a aprehender su objeto.

Solidario de la comprensión simpatética es el concepto de «libertad de la voluntad" (Willensfreiheit). Los hechos histónicos no son reductibles a una causalidad de cuño mecanicista, y, de acuerdo con el plan del historicismo, el edificio del saber ha de culminar en una metafísica de la libertad avalada por el ideal cognoscitivo de las Geisteswissen-schaften. El sujeto historicista quiere mirarse en el espejo de su más preciado atributo y forjarse con los materiales que éste le proporciona (no hará falta insistir en lo sarcástico de las realizaciones políticas de esta noción en el contexto alemán coetáneo). Las modulaciones de dicho ideal son diversas, desde la estética hasta la científico-natural (en un intento más bien naîf por rehabilitar la tradición de la vieja Naturphilosophie), ${ }^{11}$ y su común enemigo es la causalidad mecanicista, categoría vitanda para la metodología de las ciencias del espíritu.

En el contexto de la trayectoria weberiana, las críticas metodológicas pueden leerse como materiales preparatorios de su «sociología comprensiva» madura. Su conclusión debería desbrozar el camino de una teoría de la acción social que exige como instrumento analítico previo una depuración conceptual de la noción de Verstehen que la haga válida para los fines de una verstehende Soziologie independiente de las tradiciones historicista y positivista enfrentadas en el Methodenstreit. La "comprensión" propia de la "sociología comprensiva" presupone, en 
efecto, la crítica de la noción historicista del Verstehen (muy en particular, del concepto de "penetración simpatética» o Einfühlung) y se elabora sobre el patrón de la "acción racional con arreglo a fines" (zweckrationales Handeln) que, como es sabido, corresponde a uno de los cuatro tipos ideales de acción social delimitados en los «Soziologische Grundbegriffe». Tanto mejor "comprenderemos» una acción —es el núcleo del argumento de Weber - cuanto más claramente seamos capaces de descubrir los fines de la misma y de juzgar sobre la adecuación entre éstos y los medios dispuestos por los agentes para procurarlos. Poco tiene ello que ver con el concepto de Verstehen prevaleciente en la autocomprensión historicista de las ciencias del espíritu, como no sea la coincidencia terminológica (sólo que semejante coincidencia ha sido el fruto de privar de sentido a los usos canónicos del término). Debe leerse su crítica metodológica del historicismo como un serio ajuste de cuentas con una tradición de pensamiento cuyos conceptos necesita someter Weber a radical reelaboración. La crítica weberiana de la herencia de la escuela histórica es el resultado de las insatisfacciones de un neokantiano sui generis que quiere pasar por una fina criba semántica las categorías usuales de las ciencias de la cultura. De igual modo que no es posible entender cabalmente las propuestas positivas de la metodología de Weber sin proyectarlas sobre su trasfondo neokantiano, es asimismo difícil imaginarlas fuera del sinuoso proceso de reelaboración semántica del que resultan a partir de su formulación historicista.

En el programa weberiano, cl concepto de Persönlichkeit necesitaba de una reelaboración radical. La epistemología madura de Weber es un individualismo metodológico que arranca del ideal de la «ciencia de realidad" y exige, a manera de clave de bóveda, un concepto de individualidad - de "personalidad" - que sea operativo como categoría de la acción social. Ello obliga, claro está, a subvertir drásticamente los supuestos de la concepción historicista. La "personalidad" sigue siendo para Weber el paradigma de la individualidad histórica, pero ha perdido ya toda referencia al ideal de una subjetividad total. ${ }^{12}$ El científico social no aprehenderá ya esencias individuales expresadas en la historia ni aspirará a reconstruir la dinámica de dicha expresión a partir de la captación previa de una esencialidad supuesta. Por el contrario, la construcción de la personalidad es para Weber el resultado de un proceso de "selección» (Auslese) movido por la determinación de «relaciones de valor" (Wertbeziehungen) $)^{13}$ y determinado por "tomas de posición "valorativas" " ("wertende» Stellungsnahmen) ${ }^{14}$ que expresan el "interés» (Interesse) de la investigación. Lo real (wirklich) de la individualidad subjetiva es, en última instancia, inagotable (unausschöpfbar), ${ }^{15} \mathrm{y}$, al término de la "selección" que conduce a determinar los aspectos relevantes de la "personalidad», lo conocido de la subjetividad objeto de estudio no propor- 
ciona la vía de ingreso a ninguna totalidad subjetiva, por principio irreconstruible.

Al igual que a la Persönlichkeit integral le convenía como instrumento heurístico una comprensión de carácter simpatético (Einfühlung) encaminada a la reproducción de las «vivencias» en que la esencia de la personalidad se expresaba, a una "personalidad" ahora "descentrada» le corresponde por su parte un Verstehen caracterizado por determinar qué rasgos del individuo histórico son capaces de satisfacer a los intereses de la "interpretación" (Deutung). En los "Conceptos sociológicos fundamentales» ${ }^{16}$ con que se inicia el texto conocido como Economia y sociedad, ${ }^{17}$ la "comprensión de evidencia racional ${ }^{18}$ aparece netamente distinguida de la de carácter "revividor simpatético» y elevada a instrumento cognoscitivo básico de la sociología. En particular, interesarán al conocimiento histórico y social aquellos fragmentos de realidad en cuyos agentes puede descubrirse un obrar definido por la adecuación de medios a fines. ${ }^{19}$ Cuanto más se acerque la realidad social al patrón de racionalidad definido por este tipo ideal (lo que equivale a decir: cuanto más consciente sea la adopción por el agente del patrón de «acción racional con arreglo a fines»), tanto más hacedera resultará la "comprensión»; tal es su condición última de posibilidad, y no ya la reviviscencia de estados subjetivos de la personalidad, procedimiento al que Weber reduce ahora a mero aspecto psicológico (válido, si acaso, como fase preparatoria) de la investigación histórica y social.

La «libertad de la voluntad» no se libra tampoco de la crítica metodológica, como no podía ser menos a la vista de la huella de Kant en el trasfondo filosófico del programa weberiano. La necesidad de ajustar cuentas con el problema de la causalidad es patente: no en balde, la delimitación del uso de esta categoría será una de las piedras de toque de las propuestas metodológicas de Weber. Característica de la gnoseología historicista era la afirmación de una causalidad sui generis en el territorio de las ciencias de la cultura, a saber, la "causalidad por libertad" (Kausalität durch Freiheit) como categoría apta para subsumir en ella la acción libre de las individualidades subjetivas en el devenir histórico. La obra de Knies constituye un buen lugar para observar la articulación de los conceptos de personalidad y de libertad en una de sus formulaciones historicistas más típicas. Para Knies, la libertad no se concibe en términos de "ausencia de causación» ("Ursachlosigkeit»), sino, de forma singularmente representativa de la herencia romántica del historicismo ${ }^{20}$ (y también de su fraseología más críptica), como «la emanación de la acción a partir de la substancia, necesariamente individual por completo, de la personalidad" (aus der notwendig schlechthin individuellen Substanz. der Persönlichkeit). ${ }^{21}$ La irracionalidad de la acción individual puede retraducirse así a lo «racional» sui generis de la substancialidad del «sujeto 
integral», concebida como una "unidad» (Einheit) que se transforma, de manera orgánico-naturalista, en "homogeneidad unitaria» (Einheitlichkeit) dotada de una "no contradicción" interna "objetiva" " (objektive" innere "Widerspruchslogiskeit») donde radica precisamente su carácter racional (im letzten Grunde rational). ${ }^{22}$ Los conceptos de libertad y de personalidad se articulan íntimamente y, en ocasiones, se definen de manera circular. No hay, empero, para Weber, ninguna forma de causalidad especial de las ciencias del espíritu que abra el camino a una metafísica de la libertad. El descubrimiento de nexos causales ("ursächliche" Zusammenhänge; el entrecomillado no es ocioso) ${ }^{23}$ en las ciencias de la cultura constituye un instrumento cognoscitivo usual y metodológicamente legítimo (si bien sometido a la restricción de su aplicabilidad exclusiva a "fragmentos abstractos», ${ }^{24}$ no a la "realidad en cuanto tal», de la que se sigue predicando la individualidad como forma básica). Lo que no cabe, sin embargo, es la hipóstasis del uso peculiar de la causalidad en las ciencias de la cultura que señale el dominio de una metafísica especial. Según la concepción de Meyer, por ejemplo, entre el "azar» y la "libertad de la voluntad" se daría una estrecha "afinidad electiva" (Wahlverwandtschaft), responsable de la "especifica irracionalidad del devenir históricon. ${ }^{25}$ La libertad de la voluntad se interpreta además como un "hecho de la experiencia interna" (Tatsache der inneren Erfahrung) indispensable para la atribución de responsabilidad a la wactividad voluntaria» (Willensbetätigung) del individuo. ${ }^{26}$ Pero ello implica consecuencias funestas tanto para la ética como para la metodología de la historia. Weber comparará la intromisión del problema de la libertad en la metodología histórica con la interpolación de milagros cn las scries causales: ${ }^{27}$ a la historia no le cumple desempeñar «la tarea de "juez" de sus héroes" (die Aufgabe des "Richters" über ihre Helden). ${ }^{28}$ De esta forma, lo que de irracional haya on la historia no puede determinarse con las mismas pautas con que se afirma la wirracionalidad de la naturaleza" ${ }^{29}$ Las acciones sólo se dirán irracionales en la medida en que se alejen del «ideal de una acción estrictamente racional (eines rein rationalen Handelns), esto es, totalmente determinada por fines y absolutamente oricntada a los medios adecuados», ${ }^{30}$ mientras que la auténtica libertad de la voluntad en las acciones no excluye - antes bien, exige- la atribución de causa a las mismas. ${ }^{31}$

Las consecuencias de la crítica de la causalidad por libertad no son triviales en la metodología histórica de Weber, como tampoco lo son para dejar claro el juicio que le merece cualquier concepción fatalista de la historia. En un pasaje cuya importancia para comprender los supuestos filosóficos del programa weberiano es difícil de exagerar, se determina con claridad el estatuto de las dos tentaciones en pugna de la filosofía historicista de la historia: 
La estricta «necesidad» del devenir histórico concreto (die strikte "Notwendigkeit s des konkreten historischen Geschehens) queda, pues, para la historia no sólo como un ideal, sino como un postulado que se sitúa en el infinito (ein in der Unendlichkeit liegendes Postulat), y, de manera inversa, tampoco le es dado [a la historia] deducir, a partir de la irracionalidad de aquel devenir individual parcialmente cósmico, ningún concepto de una «libertad" indeterminista (einer indeterministischen «Freiheit») que sea relevante para la investigación histórica y específico suyo. La "libertad de la voluntad» ( Willensfreiheit»), de manera señalada, es para la historia algo trascendente, y concebirla como el fundamento de su trabajo es cabalmente un sinsentido. Formulado de modo negativo, es el caso que para la historia ambas ideas se sitúan allende toda "experiencia" verificable por ella, y ni a una ni a otra le es dado influir de hecho sobre su trabajo práctico. $^{32}$

Como ningún lector ignora, los términos de la argumentación weberiana remiten de manera no por tácita menos llamativa al tercer conflicto de la antinomia de la razón pura kantiana. ${ }^{33}$ La manera como el programa de investigación weberiano aborda la cuestión es absolutamente crucial, y constituye la mejor vía de acceso a las motivaciones últimas de su filosofía de la historia. El papel de una ciencia histórica depurada de la ganga historicista consiste en aclarar - de forma causal en toda la medida de lo posible - el sentido de aquellos fragmentos del pasado que caen bajo el interés de la mirada científica. Las metafísicas de la historia al uso son para tal menester irrelevantes, piensa Weber. No es difícil, sin embargo, llevar algo más lejos el alcance de sus críticas y descubrir en ellas los motivos estrictamente filosóficos de su recusación del historicismo. Puesto que conduce a antinomias que la razón teórica no puede resolver, la "causalidad por libertad" no es un concepto pertinente en la investigación histórica (como tampoco lo es la «necesidad del devenir histórico») ${ }^{34}$ La historia está lejos de ser la crónica triunfal de la libertad porque esa pretensión se sale de sus límites epistemológicos, pero -es inevitable la sospecha - también porque la causalidad por libertad tiene su casa en predios muy distintos. ${ }^{35}$ Nada nos dice Weber sobre la Kausalität durch Freiheit como categoría de la razón práctica, ${ }^{36}$ pero no es lección para echar en saco roto la que enseña a olvidar la tentación de mirar a la historia como la coartada de la moralidad, en una reivindicación de la razón práctica ilustrada que evita sumarse a su correlativa filosofía de la historia. ${ }^{37}$

La hipóstasis de las categorías epistemológicas historicistas implica, pues, dotar al sujeto cognoscitivo de atributos que Weber no desea concederle: precisamente porque la realidad fenoménica posee el ingrediente de la Unausschöpfbarkeit y en ella no habita una racionalidad presta a su espontánea captación, debe la ciencia de la cultura afinar sus herramientas teóricas de manera que le sea dado ejercitar el tipo de racionali- 
dad específico suyo. En algún lugar, Weber llegó a asociar la ocupación con la "lógica» de la ciencia a momentos que hoy estaríamos dispuestos a considerar de "cambio de paradigma". ${ }^{38}$ Los "desplazamientos fuertes de "puntos de vista" (starke Verschiebungen der «Gesichtspunkte») en el cultivo de una ciencia particular vendrían a desencadenar «la incertidumbre sobre la esencia del propio trabajo» y, con ella, sla revisión de las formas lógicas» de la disciplina, tarea encomendada más bien al propio paciente que a terapias metodológicas externas. ${ }^{39}$ Tal era en rigor para Weber el estado de la ciencia histórica en 1906, fecha de su extenso comentario a Zur Theorie und Methodik der Geschichte de Eduard Meyer (aparecida cuatro años antes). No son escasos los lugares en que Weber muestra su desafección por la práctica per se de la "lógica de la ciencia», actividad para la que en todo caso declara más apto al propio científico que al metodólogo de oficio. ${ }^{40} \mathrm{Y}$, en efecto, el contexto del trabajo epistemológico de Weber rebasa con mucho el marco de las preocupaciones de crítica interna del método. Según he tratado de esbozar, en los escritos lógicos weberianos se lleva a cabo una cumplida reconstrucción y una crítica sistemática del ideal de subjetividad supuesto por la autocomprensión gnoseológica de las ciencias del espíritu. La crítica de dicho ideal se formula mediante categorías estrictamente epistemológicas (Weber no es un dilettante en metodología), pero parece claro que a la crítica interna del método científico se hallan incorporados intereses exteriores que pueden descubrirse en otros contextos de la obra weberiana. En un momento del cscrito sobre Roscher y Knies, proclamaba Weber su malestar ante la pretensión de extraer una visión del mundo a partir de los ideales cognoscitivos de las ciencias particulares, señuelo cuyos engaños serían las propias ciencias las primeras en padecer. ${ }^{41}$ Resulta difícil, aun prescindiendo de toda noticia sobre el significado que Weber atribuía a su labor, no leer en sus críticas metodológicas la correlativa impugnación de las visiones del mundo expresadas por ciencias que manifiestamente habían caído en la seducción de aquel señuelo. La conveniencia de una tal lectura gana en justificación cuando además se tiene presente que las ciencias del espíritu y su gnoseología son precisamente el vehículo más característico de expresión de la visión historicista del mundo.

Si lo anterior es cierto, la metodología de Weber es, ella misma, crítica cultural y, de acuerdo con sus propios términos, se justifica en última instancia por serlo. En ese caso, la reconstrucción y la crítica weberianas del ideal historicista de subjetividad habrán de examinarse más allá de los límites estrictos de la epistemología. El rostro del sujeto cognoscitivo trazado por la autocomprensión historicista de las ciencias del espíritu habrá de encontrarse entonces entre los perfiles del ideal de subjetividad de la época, y su correcto escrutinio será imprescindible para hacerse una idea cabal del modelo de sujeto prevaleciente en la 
atmósfera cultural del momento. Kulturkritik y Methodenstreit pertenecen definitivamente a un mismo contexto: el del desenmascaramiento de las patologías de la subjetividad. Si ello es así, será lícito preguntarse por el lugar de ese ideal subjetivo en la lógica cultural moderna; su detallado examen proporcionará las pistas para comprender la manera como cabe descubrir las ilusiones del sujeto contemporáneo sobre su condición de usuario de la racionalidad. Y no de otra forma cabrá determinar el modo como el individuo contemporáneo se comprende en su dimensión de sujeto moral. Como algún autor ha señalado, el objeto de la «doctrina de la ciencia ${ }^{42}$ weberiana es la ética tanto como la epistemología. ${ }^{43}$ Por fortuna, la continuidad entre metodología y crítica cultural puede establecerse en más de un lugar fundamental de la obra de Max Weber. El ideal de subjetividad desenmascarado por vía metodológica aparece reproducido con asombroso paralelismo en otros escritos.

La conferencia de Munich de 1919 "Wissenschaft als Beruf" ${ }^{44}$ es el mejor punto de mira para seguir la pista del desenmascaramiento weberiano de las patologías de la subjetividad tal como fueron trazadas en los escritos metodológicos. El punto de partida de la conferencia hereda de la tradición de la crítica cultural el diagnóstico fatalista de la división del trabajo. ${ }^{45}$ La especialización creciente de los contenidos de la cultura ha llegado al interior mismo de la ciencia: el udestino del alma» del científico está empeñado en el cumplimiento escrupuloso de su labor de investigador, y la entrega a dicha tarea constituye su única seña posible de identidad. ${ }^{46}$ No cabe duda de que las observaciones webcrianas sobre el Beruf de la ciencia están trazadas teniendo cerca el modelo del científico social y de la cultura, y la conferencia puede leerse en gran parte como alegato en contra del ideal tradicional del humanista (cuyo último eslabón era el Geisteswissenschafiler), lo que contextualiza adecuadamente muchas de las referencias polémicas del texto. En la tradición de las ciencias del espíritu, el investigador de la cultura constituía el primer analogado del ideal de la subjetividad integral. ${ }^{47}$ Intérprete canónico y vicario del héroe histórico, el científico cultural exhibía en su labor cualidades que lo colocaban en la vecindad de la Persönlichkeit excelente, pudiendo así su comprensión del mundo del espíritu erigirse en la forma ejemplar del saber. El investigador de la historia señalaba así los ideales culturales hegemónicos, ejercía con ello de mediador entre el pasado y un presente ávido de identidad y se constituía en fin en árbitro último de la cultura.

A muy poco de ello, como se verá, puede aspirar el científico retratado en "Wissenschaft als Beruf». Mientras que el Geisteswissenschaftler elabora en su trabajo práctico y en su ideal metodológico el modelo de la subjetividad integral, y oficia de nuncio suyo, el científico weberiano se enfrentará a un objeto de estudio que exige un patrón de subjetividad 
fragmentario, y él mismo servirá de ejemplo de sujeto parcial, de síntoma de la escisión de la cultura. La tarea de Weber en la conferencia de Munich consiste en perfilar los contornos de una figura de la subjetividad posthistoricista, desde el supuesto de que una tal configuración del sujeto sólo se realiza de manera plural y esencialmente conflictiva. El científico es ya sólo uno de los varios tipos de personalidad practicables en una cultura de la fragmentación, y ha dejado de ser posible atribuirle rasgos de privilegiada cercanía a sujeto integral alguno. Como en el caso del político en la otra conferencia de Munich, el retrato weberiano del científico constituye la muestra más nítida de propuesta de un ideal normativo de subjetividad para el tiempo presente. Lo que confiere, empero, a "Wissenschaft als Beruf» una mayor densidad conceptual es la forma como ese ideal se elabora por contraste con la noción historicista de sujeto. Poseemos así dos patrones de subjetividad y de relación entre la racionalidad y el individuo que deviene su usuario lo suficientemente ligados en su génesis como para que nos sea dado reconstruir la dinámica weberiana de la subjetividad postilustrada.

Pero el científico no es el único paradigma del sujeto postilustrado. No es gratuito que Weber se valga de la comparación del científico con el artista para definir una figura que quiere manumitir de su servidumbre a las categorías del historicismo. En la tradición clasicista y romántica, el artista venía a ser la encarnación protolípica de la subjetividad intcgral, en manera aún más señalada que la abstracta Persönlichkeit de esa amanerada intelectualización tardorromántica que conocemos como historicismo. La historia semántica del término Erlebnis, ${ }^{48}$ no es un mal documento del proceso que conduce de la lectura schilleriana de la Critica del Juicio a la metodología de las ciencias del espíritu. Como ha señalado Gadamer, Goethe es emblemático de esta sinuosa tradición, ${ }^{49}$ y no es casual que Weber apunte al referente goetheano en lo que puede considerarse su definitivo ajuste de cuentas con la tradición del genio: la «íntima entrega a la tarea» (die innere Hingabe an die Aufgabe) y sólo a ella es el único ideal posible del artista —como el del científico- ${ }^{50}$ y la cifra de su "personalidad». ${ }^{51}$ El contraejemplo más inmediato del artista weberiano no podía ser otro que Goethe; la aspiración, goetheana por antonomasia pero típica de toda una tradición de crítica cultural que alcanza desde Schiller a las vanguardias, de "hacer de la propia "vida" una obra de arte» (sein "Leben» zum Kunstwerk machen zu wollen) ${ }^{52}$ es una de las enunciaciones más pregnantes del mito de la subjetividad integral, mientras que, para el Weber de 1919, constituye más bien una rémora de la genuina personalidad artística. ${ }^{53}$ La filiación goetheana de muchos de los temas centrales de la obra de Weber es un hecho claro, aunque insuficientemente conocido. ${ }^{54} \mathrm{La}$ visión historicista del mundo - esa derecha goetheana para funcionarios de Bismarck- elaboró a su 
modo el ideal fáustico, del que rescató la entronización del paradigma biográfico en la ciencia cultural. Hay un aspecto de la crítica epistemológica de Weber crucial para comprender las relaciones entre el mito de la personalidad total y el ideal biográfico (que constituye su manifestación literaria más característica en el contexto historicista). En el ensayo sobre Meyer, ${ }^{55}$ sale Weber al paso de la tesis de aquél según la cual el objeto de la biografía (en cuanto contrapuesto al de la historia) no es el individuo "como factor históricamente eficaz (als historisch wirksamer Faktor)", sino, por el contrario, "la personalidad en sí, en su totalidad (die Persönlichkeit an sich, in ihrer Totalität)". ${ }^{56}$ Para Weber, semejante ideal del género biográfico apunta a manifiestas confusiones de método que enmascaran a la biografía como una cpifanía de la subjetividad integral y cuya denuncia hará acortar las distancias metodológicas entre biografía e historia, invalidando la prioridad comúnmente atribuida a la primera. Sobre cuáles sean las formas de validez epistemológica de las "vivencias» biográficas realiza Weber una tipología que tiene como telón de fondo el paradigma más usual del género biográfico en la época: la vida de Goethe. Como ejemplo de "vivencia biográfica» irreductible para el historicismo a su inserción en una cadena causal, se vale Weber de las cartas de Goethe a Lotte von Stein. Contrariamente a los designios del ideal biográfico historicista, las «vivencias» expresadas en ese documento son siempre interpretables para Weber bien como «medios de conocimiento" bien como "componentes de la trama histórica", y, por consiguiente, se hallan dotadas de operatividad causal en la ciencia de la historia. $^{57}$

Resultará sorprendente que, después de sometidas a demolición tan drástica las categorías de la subjetividad historicista, el sujeto escindido no se sustraiga a su semántica: que su nombre sea también Persönlich$\mathrm{keit}^{58}$ y su atributo esencial se llame asimismo Erlebnis, ${ }^{59}$ aunque poco tengan que ver uno y otro ya con la historia conceptual que los precede. No es un dato menor el que las señas de identidad del ideal de sujeto propuesto en "Wissenschaft als Beruf" hereden los nombres de las cualidades del ideal historicista del sujeto, bien que subvertidas. Se diría que su figura está construida con materiales de derribo, lo que sólo debe mover a asombro si se ignora que la piqueta del edificio del historicismo salió forjada de la propia fragua weberiana. ${ }^{60} \mathrm{La}$ "personalidad» del científico — como la del artista - se define también por la índole de sus "vivencias», pero, frente a la espontánea articulación de los Erlebnisse de la personalidad historicista, transparentes a una comprensión simpatética que rescataba la totalidad y el centro de la "personalidad", la «vivencia de la ciencia» configura un ideal subjetivo muy otro. La separación de esferas de valor constitutiva de la lógica cultural del proceso de racionalización se ha encargado de desenmascarar el mito de la subjetividad 
integral: la indefinida transparencia de los sujetos queda ahora cegada por el surgimiento de opacidades infranqueables. El ideal de personalidad será interno a cada esfera de valor, y la comprensión de la acción habrá de llevarse a cabo presuponiendo tan sólo los tipos ideales de las formas del obrar - en particular, la acción racional con arreglo a finescaracterísticas de cada compartimiento estanco de la cultura. La labor de Weber en "La ciencia como vocación" es delimitar las condiciones de los ideales de sujeto posibles en una cultura escindida. La diferenciación de csferas de valor y el "politeísmo de los valores" constituyen datos fácticos previos a su diagnóstico de la subjetividad contemporánea; configuran el «destino de nuestra cultura ${ }^{61}$ y trazan los límites de cualquier discurso valorativo que en ella quiera darse.

Bien poco de las categorías weberianas presentes en «La ciencia como vocación» sería comprensible sin saber que constituyen el producto de la crítica de las nociones centrales de la visión historicista del mundo. Pero Weber parece haber dado en 1919 su crítica metodológica por concluida (acaso los adversarios habían dejado tiempo atrás de ser relevantes), y los mitos que ahora pugna por desenmascarar son de una generación distinta, si bien el aire de familia resulta perceptible para cualquier conocedor de sus progenitores. Los nuevos «ídolos" (Götzen) del tiempo a los que cumple desarbolar vuelven a llamarse Erleben y Persönlichkeit, ${ }^{62} \mathrm{y}$, desarraigados ya de la epistemología, configuran una retórica popular que halla en el antiintelectualismo juvenil surgido al calor de la derrota bélica terreno bien abonado. "Acumular vivencias" ${ }^{63}$ parece ser el ideal pueril de la nueva personalidad, añorante a su manera del aniquilado sujeto total. La apelación a la "vivencia" posee todas las características de lo enmascarador y, para el catedrático liberal crítico del mandarinato que habla en el invierno revolucionario de Munich, no es sino que síntoma de debilidad y nostalgia de un destino de la cultura negado ahora por la guerra sin cuartel entre las deidades del desencanto. ${ }^{64}$ Levantar, frente a las exigencias de la época, la bandera de un ideal vital cuyas condiciones de realización se hallan negadas por la lógica de una cultura que en otro tiempo cobijó la expectativa de un sujeto sin fisuras no puede ser otra cosa para el Weber de 1919 que reprobable ingenuidad. Ninguna vivencia puede ya hacer de puente entre el alma que la experimenta y la diáfana plasticidad del mundo, y lo que para el historicismo era una aspiración aún formulable como ideal intelectual es ahora mera retórica póstuma. Asir el sentido del mundo y hacer de la propia vida una obra de arte que se incardine en lo transparente de la naturaleza y de la historia ha dejado de ser una máxima que quepa erigir en ideologema eficaz. La aceleración de la dinámica cultural lo ha expulsado a las regiones más periféricas de la ideología y lo único de que puede ser emblema es ya una subcultura. Cuando el habitante del mundo de- 
sencantado piensa haber prendido con alguno de sus ideales el sentido último de la vida, hallará que no ha hecho sino adoptar uno más de entre los innumerables valores en disputa. No ocurre sólo que el mundo devenga opaco al valor y la reconciliación uno con otro se convierta en mero ensueño, sino que antes aún de medirse con el mundo, habrá el sujeto de hacer entrar su convicción en una irresoluble disputa con las encarnaciones de otros tantos valores en litigio, iguales todos en fuerzas e impotentes para vencer sobre los demás.

La adopción consciente del Beruf de la ciencia -o del arte- implica por el contrario un característico modo de pasión que excluye por sí mismo la articulación armónica de la totalidad de las pasiones del individuo y el que lo elija debe abstenerse de mirar allende su único objetivo. Al igual que quien abraza cualquier otra vocación, en su elección ha decidido ya por qué dios o en favor de qué demonio va a lidiar, e ignorar esta circunstancia de su elección implica ignorar el destino de la cultura. Tan sólo comprendiéndolo y elevándolo a consciencia, le será dado experimentar no ya un haz plural de vivencias sino la concreta vivencia por la que ha optado, y ésta con toda su intensidad. Sólo así será una "personalidad". ${ }^{65}$ La exaltación ideológica de la vivencia total no será por su parte, como se ha visto, sino indicio de debilidad, de la incapacidad de "mirar de frente al destino del tiempo en su severo rostro": ${ }^{66}$ los ídolos de la época son los falsos dioses con cuyo culto se quiere eludir la obediencia a los verdaderos que han entrado en guerra.

Para el clima mental que alienta a estos nuevos ídolos de la civilización, la lógica cultural de la modernidad es una "rutina» difícil de sopor$\operatorname{tar}^{67}$ "Rutina" $\longrightarrow$ "cotidianidad" (Alltag) - constituye, como es sabido, un término clave en la exposición weberiana del concepto de adominación carismática». ${ }^{68}$ Lo que "carisma» (Charisma) mienta en ese contexto, según los propios términos de Weber, es precisamente la atribución a una "personalidad" (la coincidencia terminológica no es casual) de cualidades "extraordinarias" (ausseralltäglich, término cuya denotación es la de *extracotidiano»). En la fase de la disolución del carisma, el proceso que adviene es el de su Veralläglichung («cotidianización», «rutinización» o, quizá mejor, «trivialización»). La búsqueda desesperada de la "vivencia» - de cualquier "vivencia" - como última tabla de salvación de la cultura tiene algo de indeterminado malestar frente a la cotidianidad, de añoranza de un carisma ignoto. Más bien que el carisma concreto de alguien, parece entronizarse la abstracta forma de lo carismático como emancipación de una cotidianidad perfilada con pareja vaguedad. Mientras tanto, a la ilusión del sujeto total desmantelada por la dinámica de la cultura resulta ciertamente fácil atribuirle no pocos de los rasgos más típicos de lo "carismático".

Es sabido que una de las ejemplificaciones más sugestivas de la no- 
ción weberiana del carisma corresponde a lo que, al final de la sección VII ( DDominación política y hierocracia») de la "Sociología de la dominación" de Wirtschaft und Gesellschaft, llama Weber "la glorificación carismática de la "Razón" " ${ }^{69}$ Lo escueto de la presentación del concepto de un "carisma de la Razón" y la ausencia de otros desarrollos explícitos en la obra de Weber que prolonguen por alguna vía esta denuncia de lo quc de carismático hay en la desencantada racionalidad de la Ilustración hacen de la cuestión un rarum de la red categorial weberiana. ${ }^{70}$ Todo intento de superponer tan resbaladiza categoría sobre el diagnóstico weberiano de la cultura contemporánea se expone a riesgos que no convicne dejar libres de cautela. En particular, falta en Weber cualquier observación sobre los rasgos que, en su condición de carisma, definen a aquello que de carismático llegó a tener episódicamente la razón ilustrada; extraer, pues, las últimas consccucncias de lo que acaso sea mera analogía corre el riesgo de convertir en central algo que, al pie de la letra, no es sino una observación no agotada en su capacidad explicativa.

¿Cabe, pues, en rigor, entender las ilusiones del historicismo -incluida su tentación providencial, que formaba parte integrante del «carisma racional"- como un episodio de ese sueño de la razón que es su apoteosis carismática? Ciertamente, la pregunta sólo puede plantearse a condición de erigir lo carismático en dimensión estructural de la racionalidad contemporánea (o en tentación ocasional suya, si se prefiere) y si se está dispuesto a comprender la observación de Weber sobre el culto revolucionario de la Diosa Razón como un ejemplo simbólicamente característico entre otros posibles más bien que como un acontecimiento histórico individual irreductible a los efectos de toda determinación causal. Que esta segunda estrategia no sería weberianamente ortodoxa es algo que habrá quedado claro después del apresurado repaso a la crítica metodológica de Weber que el lector habrá tenido ocasión de efectuar páginas atrás. En el caso, pues, de que nos sea dado entender el «carisma de la Razón" con rigurosa coherencia respecto de la exposición weberiana de los rasgos de lo carismático, no parecerá demasiado ilícito enhebrar ese inquietante cabo suelto de su aparato conceptual en el tejido al que más verosímilmente pertenece. Si cabe hablar de un carisma de la razón -que, precisamente, no es sino el «último carisma»- en la forma típico-ideal que posee la exposición weberiana de lo carismático, resulta obligado buscar la ejemplificación del mismo en ámbitos ajenos a la estricta sociología política (la Razón con mayúscula no es una categoría reductivamente política), así como conferir plena plausibilidad al concepto de una "trivialización» de ese carisma que lo devuelva al dominio de lo cotidiano y ordinario. Si carismática era la personalidad historicista, no otra cosa que trivializaciones del carisma serán los ídolos contemporáneos de la vivencia y de la personalidad. 
Fuera ya de las categorias de Weber, la subjetividad investida de los atributos de lo extraordinario, la figura de una personalidad a la que prestan el carácter sus vivencias y todas ellas, y que gana su valor con su propia espontaneidad vital tiene un nombre propio conocido en la historia de la cultura. Aunque se haya querido ver en temas weberianos afines -y en absoluto es inexacta tal vision- un fuerte eco de Goethe, hay otro clásico que late bajo la argumentación de Weber, y no es otro que Schiller. ${ }^{71}$ Cuando Weber impugna la posibilidad de encamación de una subjetividad armónica y espontánea, su crítica de la sensibilidad contemporánea podría muy bien leerse sin violencia como la partida de defunción del alma bella schilleriana:

Un alma se llama bella cuando el sentido moral (das sittliche Gefuht) ha llegado a asegurarse a tal punto de todos los sentimientos del ser humano (aller Empfindungen des Menschen), que puede abandonar la dirección de su voluntad al afecto y no corre ningún riesgo de estar en contradicción con sus decisiones. De ahí que en un alma bella no sean en rigor morales las distintas acciones, sino el carácter todo (der ganze Charakter) (...). El alma bella no tiene otro mérito que el hecho de ser. Con una facilidad tal que parecería que obrara sólo el instinto, cumple los más penosos deberes de la humanidad, y el más heroico sacrificio que obtiene del instinto natural se presenta a nuestros ojos como un efecto voluntario precisamente de ese instinto (...). En un alma bella, todos los contornos tajantes se han esfumado, y sin embargo la figura integra resalta en forma tanto más verdadera, viva, armoniosa. ${ }^{72}$

Abandonar al afecto la dirección de la voluntad y armonizar la totalidad de los sentimientos de manera que el sentido moral parezca brotar de ellos de forma natural no es ya posible, y, como nos parece señalar Weber, cuando el individuo proclama su anhelo de una tal subjetividad y pretende derivar su "personalidad» de la totalidad de sus sentimientos -ahora llamados "vivencias»- no constituye en absoluto la realización del ideal del alma bella y sí alguien ciego para con el destino de la cultura. Más bien que un alma bella, encarna su caricatura trivializada, mientras que sus vivencias - que en la subjetividad no escindida resultaban igualadas como manifestaciones de una misma "gracia" (Anmut, Grazie) - ${ }^{73}$ resultan ahora mudas y no conforman figura alguna verdadera, viva ni armoniosa. ${ }^{74}$ Se diría que el individuo contemporáneo aspira a ser portador de un carisma que ya no puede ser tal, tanto porque los verdaderos carismas han entrado en guerra cuanto porque en verdad sólo aspira a un carisma en avanzado estado de rutinización. El empleo de este concepto no puede ser ajeno a los ecos schillerianos que el término "carisma" evoca. El gr. khârisma deriva de kháris ("gracia", lat. gratia), que en alemán viene traducido por Gnade, por Grazie y por Anmut. El surgimiento del carisma es en la "sociología de la dominación" de 
Weber lo único que puede romper la cotidianidad (Alltag) de la dominación tradicional o de la legal-racional, y, antes de su inevitable Veralltäglichung, debe su vigencia a lo excepcional de su circunstancia (o a la consideración de tal por los seguidores) ${ }^{75}$ El carisma implica, pues, un estado de gracia, o, como en el caso del ethos aristocrático descrito por Max Weber en un lugar de "Wahlrecht und Demokratie in Deutschland", ${ }^{76}$ de "Anmut und Wirde» ("gracia y dignidad»), lo que no en vano corresponde a los atributos del alma bella y al propio título del ensayo de Schiller antes citado.

Perdida la gracia (en el caso de la sociología política, una vez desaparecido el jefe carismático), el carisma se rutiniza y degenera en pálida sombra de lo que fue. Vuelve la «cotidianidad» - aquello que según Weber tan difícil de soportar resultaba a los jóvenes alemanes de 1919que tan sólo un nuevo carisma podrá romper. Cuando el alma bella ha perdido la gracia, el carisma se ha trivializado. Al igual que el heredero del jefe carismático está ya desposeído de carisma y tan sólo conserva el aparato ritual, así la juventud antiintelectualista que escuchaba a Weber en Munich se limitaba a querer poseer los rasgos externos del alma bella y creía poder ser tal por la sola vivencia de sus sentimientos. Pero cuando el alma bella pierde la gracia (que, según la fábula, es gratuito regalo de Venus), sus sensaciones han quedado despojadas de valor e igualadas en su insignificancia. Querer acumular vivencias sin cuento no es, en efecto, sino patética debilidad. La «batalla sin solución posible» en que han entrado "los órdenes diferenciados de valores del mundo" (die verschiedenen Wertordnungen der Welt $)^{77}$ ha disuelto la ilusión de una cultura integral (característica, central donde las haya, del ideal de Bildung del clasicismo) y rompe con el ideal de la armonización de las facultades de la vida subjetiva. ${ }^{78}$ Nietzsche y Baudelaire son los signos de la época, muy lejos ya de Goethe y de Schiller. ${ }^{79}$ Atribuye Weber en la conferencia de Munich la pérdida de la unidad del valor al desencantamiento de un mundo gobernado dos mil años por la ética cristiana. Ello no ha de impedir, sin embargo, abrir un espacio en el relato weberiano para ese otro intento, rápidamente frustrado, de instaurar un nucvo orden clausurado de valores y de aunar toda experiencia en el registro único de una subjetividad triunfal que podemos subsumix bajo el concepto de carisma de la razón. Si en verdad la razón ha sido carismática y ese carisma es el último de los conocidos, lo postcarismático de nuestra cultura habrá de definirse en relación privilegiada con él. El sujeto desvelado como imposible cuya sombra supersticiosa oscurece al destino de la cultura no será ya tanto el alma cristiana de una tradición inmemorial cuanto esa otra efímera alma ilustrada ahora reducida a espectro, a ídolo que abastece todavía al apetito de ilusiones de la civilización. ${ }^{80}$

Una inadecuada estrategia de lectura de "Wissenschaft als Beruf» 
sería la que viera en ella un pliego de descargo en favor de las figuras contemporáneas de la razón y del sujeto. No todo pesimismo ha de ser necesariamente cínico ni complaciente, y, si pesimista es el pathos del diagnóstico de Weber, ello no autoriza a atribuirle un perverso amor fati por los resultados de la historia del racionalismo occidental. Sin embargo, el malestar frente a los males del presente no exige adherir con entusiasmo a las mistificaciones consolatorias del mismo. Ilustrado a fuer de iconoclasta, el empeño de Weber parece rescatar algunas de las dimensiones imprescindibles de toda crítica de la razón contemporánea que no dimita de su problemática aspiración a la racionalidad (acaso el principal motivo para no abjurar por completo de nuestra problemática herencia ilustrada sea que no podemos imaginar sin repugnancia el regreso de los ídolos que ya hemos hecho caer). No fue Weber el primero en apuntar al lado mitológico de la razón, pero sí el más coherente en hacer suyas razones que desvelaran lo que de ídolo hay en ellas. Su crítica de la cultura tiene, así, no poco de autocrítica de la razón ilustrada, mientras que su examen minucioso de las patologías del sujeto es al mismo tiempo la desilusionada exploración de las formas de subjetividad que aún pueden abrirse paso tras el derribo de un sujeto heredero de los excesos de la razón. Pero los ideales de sujeto que Weber tratará de definir siguen formando parte de la constelación de la racionalidad ilustrada, aunque ya no giren en tomo a un astro central. $Y$, por lo pronto, el sujeto de la Ilustración postcarismática no se sustrae a aquella problematización, característicamente ilustrada, que busca cómo definir lo que de sujeto moral pueda tener el sujeto sin más: el ideal weberiano del sujeto es, antes que nada, un ideal normativo.

El "politeísmo de los valores" constituye el correlato moral de un sujeto fragmentario y, a fortiori, de esa fractura de la razón ilustrada que adviene cuando se constata que el único carisma posible de la razón es un carisma trivializado. Mostrar cuáles pueden ser los ideales normativos de las figuras fragmentarias de subjetividad cs, por su parte, la preocupación de Weber una vez decretado el politeísmo de los valores que caracteriza al "destino del ticmpo". Interesa, no obstante, notar que en la caracterización del ideal subjetivo de la época entra un elemento extraño a la vena pesimista que impregna "Wissenschaft als Beruf». "Nada hay de valioso para el ser humano en cuanto ser humano que éste no pueda llevar a cabo con pasión (was er nicht mit Leidenschaft tun kann)", ${ }^{81}$ apostilla Weber para describir la "vivencia» que configura el «destino del alma» del científico. Sería desorientador pasar por alto esta apelación weberiana a la pasión, islote de vocabulario de las convicciones en el piélago del lenguaje de la responsabilidad: el sujeto escindido no es un mero calculador de consecuencias, y da la impresión de que no hay ética de la responsabilidad sin una decidida convicción que la sus- 
tente. Aunque no sea éste el lugar de discutir en toda su profundidad la tipología de Weber (cuyo locus clásico son precisamente las dos conferencias de Munich) ni de explorar los variados ecos contemporáneos del problema, acaso la contextualización de la reflexión ética weberiana en el marco de su crítica cultural sirva para recuperar algunos contenidos de la Verantwortungsethik con frecuencia oscurecidos cuando se acude a la otra conferencia de Munich para documentar sus rasgos principales. La «ética de la responsabilidad» no es, contrariamente a un uso de la expresión que tiende a hacerse moneda corriente en los ámbitos más dispares, patrimonio exclusivo de políticos pragmáticos y de su séquito de mandarines. Su formulación en "Wissenschaft als Beruf» puede ser un buen antídoto contra las simplificaciones. ${ }^{82}$ Sobre valores, sentencia Weber, no se juzga ni se decide a la luz de los hechos ni con su ayuda: al igual que al científico social no le es dado sancionar - en cuanto hombre de ciencia- la validez de tal o cual valor ni prestar apoyo racional a este o aquel credo o ideología como resultado de sus tesis científicas, el individuo en general se halla cn la elección de sus valores parecidamente huérfano de la posibilidad de recurso a cualquier ayuda de carácter factual; tampoco en el terreno de la elección moral es lícito inferir valor alguno a partir de sus motivaciones o consecuencias fácticas. Expuesto al politeísmo de los valores, el sujeto moral weberiano sirve de solitario campo de batalla a una encarnizada lucha de dioses y demonios cuya resolución no admite componendas, pero el politeísmo no es un relativismo, y en el interior del campo de batalla no rige la cláusula «todo vale», por más que carezcamos por entero de medios fácticos que nos abran de par en par la puerta de lo valioso y lo reprobable ${ }^{83}$ El paradigma del sujeto moral será el individuo que elige «libremente" su Beruf. Con todo, en esa elección, en el saldo de la correspondiente disputa de dioses y demonios, late, apagada ya la ilusión de la plena realización de lo humano, una íntima dignidad que no excluye la excelencia ni el coraje: el preferidor de valores que Weber propugna tiene poco que ver con el individuo hiperestésico abandonado a su propia anomía. (Al menos en esto, y por más que el lugar que se le ha asignado a la moral no sea precisamente optimista, quizá hayamos en el final del siglo de reconocernos aún más pesimistas que el sombrío Weber, siguiendo sin poseer asidero alguno para la ética fuera de nuestra propia reflexividad y dando por perdidas además las virtudes necesarias para tomar parte en batallas como las descritas).

Entre valores sin conciliación posible, trátase, pues, de decidir. ${ }^{84} \mathrm{Y}$ la decisión no es algo baladí, pues compromete a la existencia entera (aunque, sin paradoja, «entera» ya no valga en el sentido de «total»). El tema goetheano del pacto diabólico no es ajeno a esta cuestión. «Bedenkt, der Teufel, der ist alt, so werdet alt ihn zu verstehen" ("Acordaos de 
que el diablo es viejo y haceos viejos para comprenderlon), reza un proverbio que cita Weber. ${ }^{85}$ Sólo tomando partido por una de las deidades en litigio, podrá el individuo contemporáneo seguir ejerciendo como sujeto, y para dicha empresa le resultará imprescindible saberse cumplidor de un designio inevitablemente parcial y expuesto al conflicto: acabar con ese demonio exige hacerse aliado suyo para conocer bien sus arcanos. ${ }^{86}$ El individuo que elige su demonio se sigue alimentando del ansia de vivencia y del anhelo de verdadera pasión, si bien bajo la forma de la nostalgia. Ignorante de su parte en el destino, cree poderse confiar todavía a unos afectos que ya no le son leales y desconoce que las únicas pasión y vivencia posibles que le aguardan presuponen la renuncia a la armonía de sus vivencias y sus pasiones. Pero el anhelo es insuficiente. La manera de obedecer al demonio que gobierna la existencia propia no es otra que la respuesta a "las exigencias de cada día» (die Forderung des Tages), ${ }^{87}$ mandato que hace recordar la imposibilidad de carismas extracotidianos.

Consecuencia de ello es el reforzamiento de la tesis de la Wertfreiheit o "neutralidad valorativa" aludida en "Wissenschaft als Beruf» y expuesta en otros ensayos metodológicos. ${ }^{88}$ La toma de partido del científico en la disputa de dioses y demonios implica su obediencia a los solos mandatos de la esfera científica, que no son otros que el idcal de la objetividad y la abstención de toda valoración subjetiva o interesada. Tratar de adoptar otra función significa para el científico ignorar su destino y querer suplantar al predicador, al reformador social o al profeta, además de defraudar —como señala Weber en varios lugares- la confianza que el Estado ha depositado en él y de crigirse en voz privilegiada que no admite respuesta posible cn las aulas. ${ }^{89}$ Ya vimos cómo la vocación científica no era posible sin pasión ni sin vivencia (bien que de una índole que podríamos llamar "postcarismática») y éstc es el momento de comprobar que la neutralidad valorativa y su correspondiente "pacto con el diablon implican la asunción de contenidos éticos esenciales, que en manera alguna permiten entender el politeísmo de valores como un relativismo. La moral del científico, tal como la esboza Weber en la conferencia de Munich, constituye un ejemplo de "ética de responsabilidad", algunos de cuyos imperativos se mencionan de soslayo. Así, el de una modalidad de agitación de las conciencias que a Weber se le antoja inseparable de la función docente y científica: enseñar a los alumnos ${ }^{90}$ a saber reconocer los hechos «incómodos» (precisamente aquellos que, para la corriente de opinión prevaleciente entre los estudiantes, sean más «difíciles de admitir»). ${ }^{91}$ El ejercicio de esta tarea constituye el principal «tributo ético» (sittliche Leistung) del docente, y no es posible sin el ideal de la "neutralidad valorativa". Habla de ello Weber como de una trivial evidencia. No parece que lo sea tanto cuando se la coloca junto al otro 
imperativo a que viene obligado el hombre de ciencia en la época de su especialización y que define adecuadamente a qué valores obedece la neutralidad valorativa misma. Se trata de la misión del científico - es claro que Weber piensa en el científico de la cultura, antaño sacerdote del culto a la transparencia de la razón- de aclarar y explicitar la lógica misma que la valoración posee. En una cultura de la decision, el científico está llamado a definir aquellas decisiones que sean posibles y a elucidar sus supuestos y consecuencias. Cuando el científico adopta responsablemente este papel y al mismo tiempo renuncia a defender cualquier valor que no sea el de la neutralidad en la exposición de su disciplina, está cumpliendo los mandatos de su demonio y contribuyendo a aclarar cuálcs son los demonios a que en general puede servirse y cómo:

Con esto llegamos ya al tributo último que la ciencia como tal puede ofrecer al servicio de la claridad, $c$ igualmente a sus limitaciones: podemos $-\mathrm{y}$ debemos - decirles a ustedes que tal o cual toma de posición de carácter práctico (die und die praktische Stellungsnahme) produce tales y cuales consecuencias internas, $\mathrm{y}$, así, tener la honradez de deducir dichas tomas de postura, de acuerdo con su propio sentido, de tal o cual posición fundamental última relativa a una visión del mundo (aus der und der letzten weltanschauungmässigen Grundposition) -puede scr que deriven de una sola o quizá de varias diferentes-, pero de ella y en ningún caso de otra. Dicho de manera figurada: servís a este dios y ofendéis a este otro si os decidís por tal toma de postura. Llegaréis, pues, necesariamente, si permanecéis fieles a vosotros mismos, a tales y cuales consecuencias internas, últimas y significativas. (...) Así pues, si somos conscientes de nuestro cometido, (...) podemos determinar a cada uno, o al menos ayudarlo, a que dé cuenta por sí mismo (sich selbst Rechenschaft zu geben) del sentido üttimo de su propio obrar (über den letzten Sinn seines eigenes Tuns). ${ }^{92}$

Así sirve la ciencia a su demonio, uno de los innumerables a los que el hombre contemporáneo puede encomendarse. Y, cuando el científico desempeña adecuadamente su vocación, acoge al mismo tiempo bajo su mirada a todos los demás dioses y demonios, aunque su mirada se enfoque desde la lejanía, y precisamente porque sólo desde la distancia puede y debe enfocarse. La acción responsable del científico - como la del político en la otra conferencia de Munich- es un paradigma de la acción responsable del individuo en una cultura escindida. Lo que con su retrato ha pintado Weber es más bien la forma en la que cabe pensar al sujeto contemporáneo como sujeto moral, y esa viene a ser la más inquietante de sus lecciones. Convicción y responsabilidad se articulan en él de manera compleja; ninguna de las dos parece posible sin la otra, limitándose de manera recíproca, y el mandato de pensar las responsabilidades propias se constituye en el primero de los imperativos morales, que no puede cumplirse sino con una extraña y huidiza pasión. Sectario 
de un culto entre muchos, el científico comparte con sus contemporáneos un mundo politeísta en donde, al igual que el hombre de ciencia sólo puede ser agradable a su dios de forma apasionada, todo ser humano ha de satisfacer las "exigencias de cada día" con parecida fuerza de ánimo. Que dicha pasión ya no puede estar adornada del carisma de la gracia es un dato del destino. Pero, volviendo a Schiller, debe recordarse que al alma bella le cumple dar un definitivo paso en orden a su perfección:

El alma bella debe (...) transformarse en alma sublime, y ésta es la infalible piedra de toque por la cual se la puede distinguir del buen corazón o de la virtud por temperamento. Si en un hombre la inclinación está de parte de la justicia sólo porque la justicia está afortunadamente de parte de la inclinación, el instinto ejercerá, en el afecto, un completo poder coactivo sobre la voluntad; $\mathrm{y}$, cuando sea necesario un sacrificio, será la moralidad y no la sensorialidad quien lo haga. Si en cambio ha sido la razón misma la que, como ocurre en el carácter bello, ha tomado a su servicio las inclinaciones y ha confiado provisionalmente el timón a la sensorialidad, se lo retirará en el mismo momento en que el instínto quiera abusar de sus poderes ocasionales. La virtud por temperamento desciende, pues, en el afecto, a mero producto natural; el alma bella trasciende a lo heroico y se cleva a la pura inteligencia. La dominación de los instintos por la fuerza moral es "libertad de espiritu" y dignidad se llama su expresión en lo fenoménico. ${ }^{93}$

La fenomenología schilleriana del alma bella constituye uno de los mitos ilustrados por antonomasia. El malestar por las insuficiencias de la razón (en Schiller la razón práctica kantiana) busca remedio en esa otra razón enfática que cree poder ser una con el instinto y mito al tiempo que verdad. Sólo al alma bella le es dado llegar a ser alma sublime, libre ya de los peligros de abrazarse al mero instinto. Pero la razón misma empezó pronto a desconfiar de que alguna vez pudiera tener los instintos a su servicio y confundirse con ellos: en un tercer y definitivo momento que Schiller quiso olvidar, el alma sublime descubre que no fue jamás alma bella salvo en el relato de un mito consolador. Algo de eso le ocurre al sujeto fragmentario de Weber y algo de eso notamos a través suyo que le ha acaecido a la razón ilustrada. La metodología científica y la crítica de la cultura de Max Weber convergen en la denuncia de lo que quizá no sea desafortunado llamar el «mito de la transparencia de la razón". El ideal de un sujeto total arrastra tras de sí la ilusión de una composición armónica de las facultades de la vida espiritual, único contexto en que la razón se deja decir de manera carismática. Aliadas de los hados (criatura tan esclarecida sirvió a señor así de ciego), las luces de la Ilustración imaginaron poder iluminar «un nexo que va abarcando sin interrupción la acción plena de sentido" (ein stets umfassender Zusammenhang sinnvollen Handelns) y tornar "transparente "desde den- 
tro" ("von innen heraus" durchsichtig) ${ }^{94}$ la raíz última de la que conocimiento y acción, autorrealización y felicidad no eran sino espontáneos frutos. Pero después de desvelado el engaño, acaso quepa acudir a una dignidad que ahora ya no podrá valerse del auxilio de la gracia. ${ }^{95} \mathrm{Digni}_{\text {- }}$ dad sin gracia es una divisa posible para la razón contemporánea, despojada de carisma y heredera suya. Cuando las vivencias ya no conspiran entre sí para constituir una personalidad armónica, la libertad del espíritu se habrá de atener tan sólo a la fuerza moral que permita elegir vivencias dignas. ${ }^{96}$ Aspirar a convertirse en alma sublime a sabiendas de que no se es un alma bella viene a ser el imperativo de los tiempos: la nostalgia de la gracia se ha vuelto enemiga de la búsqueda de la dignidad. ${ }^{97}$

La relación de la razón contemporánea con su historia (con aquella reconstrucción de la misma que su parcialidad produzca) nos sitúa en un lugar lejano a su transparencia. Nuestra imagen de la razón ilustrada - como la del sujeto a ella ligado - sólo se nos da reconstruyendo el proceso que conduce a su fragmentación. Los usos de la razón se ha vielto opacos, y sólo imaginamos una razón transparente en el ejercicio de nuestra propia opacidad. Medir nuestra distancia de las formas clásicas de la razón ilustrada constituye, en último término, un ejercicio de autodefinición. Al igual que la modernidad triunfal -que no es sinónimo de modernidad cumplida- definía sus perfiles por referencia a un ideal clásico, así la crisis de la razón ilustrada tiene también sus griegos -que no somos nosotros- y contempla con perplejidad sus ruinas, harto distintas de las de Pompeya. Nuestro clasicismo y nuestros monumentos son ya los de la propia modernidad. Cuando el uso práctico de la razón se vuelve reflexión sobre su caída en desuso, los imperativos de la racionalidad moral pasan a elaborarse en un idioma distinto del que le correspondía en la era de su transparencia: no podemos reconocernos hablantes del lenguaje de la razón ilustrada, aunque no por ello renunciemos a elaborar metalenguajes que la pongan entre comillas. Examinar los velamientos de la razón que nos la han hecho opaca sigue siendo la manera menos indigna de practicar una racionalidad fragmentaria.

\section{NOTAS}

1. Cfr., p, ej., Karl-Otto Apel, «Das Problem einer philosophischen Theorie der Rationalitätstypen», en H. Schnädelbach (Hrsg.), Rationalität. Philosophische Beiträge, Francfort, Suhrkamp, 1984, pp. 15-31. Sobre la connotación posfilosófica de una racionalidad ya no expresable en el lenguaje de Ia Venumfi, vid. la introducción de Herbert Schnädelbach a dicho volumen (pp. 7-14). Un lugar que se ha hecho ya imprescindible sobre la cuestion es la antologia de K. Baynes, J. Bohman, Th. McCarthy (eds.), After Philosophy. End or Transfomation?, Cambridge (Mass.), The MIT Press, 1987.

2. En expresion de Richard J. Bernstein. Cfr. su «The Rage Against Reason", en Ernan 
McMullin (ed.), Construction and Constraint. The Shaping of Scienific Rationality, Notre Dame (Indiana), University of Notre Dame Press, 1988, p. 198.

3. Como lo juzga Steven Lukes. Cfr. "Some Problems About Rationality", en Bryan Wilson (ed.), Rationality, Nueva York, Harper \& Row, 1971, p. 207. Referencia imprescindible sobre el concepto de racionalidad en Weber es S. Kahlberg, «Max Weber's Types of Rationality: Cornerstones for the Analysis of Rationalization Processes in History", American Joumal of Sociology, 85, 5 (1980), pp. 1145-1179. Un ponderado análisis del problema se hallará en Luis F. Aguilar Villanueva, «En torno del concepto de racionalidad de Max Weber", en León Olivé (ed.), Racionalidad. Ensayos sobre la racionalidad en etica y política, ciencia y tecrología, México, Instituto de Investigaciones Filosóficas (UNAM)-Siglo XXI, 1988 , pp. $76-98$.

4. La expresión es de Javier Muguerza (vid. «La razón con minúscula o por qué somos postmodernos», en Manuel Cruz, Miguel Angel Granada, Anna Papiol (eds.), Historia, lenguaje, sociedad. Homenaje a Emilio Lledó, Barcelona, Crítica, 1989, pp. 424-430, y «Sobre la condición metafísica ylo postmetafísica del sujeto moral», ms. inédito).

5. Clr. Giacomo Marramao, Poder y secularización, traducción de Juan Ramón Capella, prólogo de Salvador Giner, Barcelona, Peninsula, 1989, pp. 130 ss. «En Weber, la estructura constituyente del vínculo social no viene ya dada por la relación individuo-sociedad, sino por la relación entre racionalidad y formas del obrar. El individuo ya no es, como en la tradición clásica occidental, la célula de la sociedad. La posibilidad de representarse esta última como una totalidad o un organismo que tiene en los individuos sus "partes vivientes" queda ya definitivamente superada.s (Op. cit., p. 132).

6. Ibid.

7. En su conocido discurso necrológico, Karl Jaspers no dejó de apuntar la filiación entre el carácter fragmentario de la obra de Weber y su consciencia de la época. Vid. $\mathrm{K}$. Jaspers, Conferencias y ensayos sobre historia de la filosofia, Lraducción de $\mathrm{R}$. Jimeno Peffa, Madrid, Gredos, 1972, pp. 330-347. Debo a Julián Sauquillo haberme llamado la atención sobre este texto.

8. Vid. Wilhelm Hennis, «Personality and Life Orders: Max Weber's Theme», en Scott Lash, Sam Whimster (eds.), Max Weber, Rationality and Modemity, Londres, Allen \& Unwin, 1987, pp. 52-74.

9. Cfr. Max Weber, «Roscher und Knies und die logischen Probleme der historischen Nationalökonomie», en Gesammelte Aufsätze zur Wissenschaftslehre, sechste, erneut durchgesehere Auflage, hrsg. von Johannes Winckelmann, Tubinga, J.C.B. Mohr (Paul Siebeck), 1985, p. 6. En adelante, citaré simplemente $W L$ los textos recogidos en esta recopilación.

10. El ideal metodológico historicista de la "personalidad total no está exento de connotaciones que lo retrotraen a la concepción romántica del Volksgeist. En efecto, el individuo total gnoseologicamente apuntalado calca su estructura de la "personalidad" igualmente unitaria del "pueblo»; el individuo y la comunidad nacional son, asf, dos muestras, isomorfas en su concepción, de la noción historicista del sujeto. La formulación de Knies, duramente criticada por Weber, es ejemplo eminente de lo anterior; para Knies, wo más propion (die Eigentümlichkeit) del ser humano considerado por separado (des einzelnen Menschen), al igual que de la totalidad del pueblo (wie die eines ganzen Volkes), «fluye de un manantial únicon (aus einem einheitlichen Springquell erschliesst), y este es el indicio de la stotalidad" a que remite ael entero conjunto de los fenómemos de la actividad humana (alle Erscheinungskreise der menschlichen Tätigkeit)" (Cfr. WL, p. 141). "La vida personals - sefialaba Knies- - y la falta de un punto medio unitario (Mangel eines einheitichen Mittelpurktes) es una contraposición contradictoria; tan sólo donde se descubre una cosa se halla la otra». (Knies, Die poittische Oekonomie vom Standpunkt der geschichtlichen Methode (1853), p. 247, cit. por Weber, $W L$, p. 138, nota 1).

11. No faltaron en el tardohistoricismo intentos de reverdecer temas de la Naturphilosophie por medio de un uso irrestricto del concepto de Einfühlung. Así, por ejemplo, Lipps: "La categoría de "penetración simpatética" (Einfühlung) no se limita en modo alguno, se- 
gún Lipps, a los procesos "psíquicos". Por cl contrario, también "penetramos simpatéticamente" (fuhlen ein) en el mundo físico en cuanto "vivimos" sensitivamente (gefuhlmässig enleben) sus componentes como expresión de una "fuerza", de un "esfuerzo", de una "ley" determinada, etc. (p. 188), y, según Lipps, esta causalidad individual antropomorfa de la naturaleza, directamente "vivible" de modo fantástico (phantastisch erlebbare), es la fuente de las "bellezas naturales" ", Cfr. WL, p. 107.

12. "Tanto más se desvanece con ello ese retorno romántico-naturalista de la idea de "personalidad" que, por el contrario, busca la sacralidad auténtica de lo personal (das eigentliche Heiligtum des Persönlichen) en el sordo, indiferenciado "subsuelo" vegetativo de la vida personal (in dem dumpfen, ungeschiedenen vegetativen "Untergrund" des persönlichen Lebens), vale decir, en esa "irracionalidad" que no se apoya sino en la maraña de un sinnúmero de determinaciones psicofísicas del desartollo del temperamento y del temple de ánimo (...). Es este romanticismo, pues, lo que está detrás del "enigma de la personalidad" (Rätsel der Persönlichkett) de que habla Treitschke esporádicamente, y muy a menudo otros muchos, y con el que, alli donde es posible. se procura introyectar la "libertad de la voluntad" a la esfera de la naturaleza." Cfr. WL, p. 132.

13. Cfr. WL: pp. 123 y 253.

14. Vfd, nuevamente $W L$, p. 253.

15. "(...) la inagotabilidad (imausschöpfbarkeit) de un contenido con respecto a los posibles puntos de contacto (Anknüpfungspunkten) de nuestro interés es la característica de "más alto" rango de las individualidades historicas." (WL, p. 253). Raymond Aron ha comentado bellamente este paso del escrito sobre Meyer aludiendo a la "riqueza póstuma" de todo objeto cultural (cfr. R. Aron, La philosophie critique de lhistoire. Essai sur une théorie allemande de l/histoive, nouvelle édition revue et annotée par Sylvie Mesure, París, Julliard, 1987, p. 246). Es importante señalat cómo esta "inagotabilidad” de los contenidos culturales -extraida a partir de la concepción rickertiana-constituye un referente polémico frente al ideal historicista de un "rescate" de "totalidades" de contenidos.

16. "Soziologische Grundbegrifle», WL, pp. 541-581.

17. Sobre las circunstancias de este texto, tenido a menudo por la «obra" de madurez de Max Weber, vid. Wollgang Schluchter; "Wirtschaft und Gesellschaft: Das Ende eines Mythos", en Religion und Lebensfuhrung. Bd. 2. Studien zu Max Webers Religions- und Herrschaftssoziologie, Francfort, Suhrkamp, 1988, pp. 597-634.

18. "Toda interpretación (Deutung) tiende, como en general toda ciencia, a la eevidencia” (Evidenz). La evidencia de la comprensión puede ser [a)] racional (y ésta bien lógica, bien matemática) o [b)] ser de carácter revividor simpatético (einfühlerd nacheriebenden) (emocional, artístico-receptivo)." ( $W L$, p. 543).

19. "El máximo grado de "evidencia" corresponde a la interpretación racional con arreglo a fines (zweckrationale Deutung). Debe entenderse por comportamiento racional con arreglo a fines (zweckrationales Sichverhaiten) aquel que se orienta exclusivamente a medios que se representan (de manera subjetiva) como adecuados a fines que se adoptan de manera (subjetivamente) unívoca.» («Ueber einige Kategorien der verstehenden Soziologie», WL, p. 428.)

20. Weber señala explicitamente en su crítica de Knies la deuda de éste para con la doctrina organicista del derecho natural que, por medio, de la escuela histórica, deja sentir su influencia en atodos los ámbitos de investigación de la cultura humana». Cfr. $W L$, p. 138.

21. Ibid.

22. Ibid.

23. Cfr, WL, p. 136.

24. Ibid.

25. Cfr. WL, p. 221.

26. Cfr. WL, p. 222 .

27. Cfr. $W L$, p. 225. 
28. Cfr, WL, p. 222.

29. "En manera alguna el concepto de "libertad de la voluntad" debería ser puesto en relación con el de irracionalidad. Precisamente quien es empíricamente "libre" -es decir, quien no actứa sino reflexivamente (nach Erwägungen) - está, en la medida de la situación objetiva, vinculado de manera teleológica a los medios, diferentes y reconocibles, con que lograr sus fines, (Cfr, WL, p. 133).

30. Cfr. WL, p. 227.

31. "Hay ligamen causal (kausale Verknitpfung) sin teleología, pero no conceptos teleológicos sin reglas causales.» (WL, p. 86́). Advierte Weber a continuación contra la confusión entre el ideal de una metodología "teleológican opuesta al uso de la categoría de causalidad eficiente y lo que Rickert llamó "construcción teleológica de los conceptos" (teleologische Begriffsildung), expresión con la que quería denotarse en la terminología rickertiana la ordenación del material empírico a "relaciones de valor». (Ibta.).

32. Cfr. $W L$, pp. 136-137. En otro lugar del escrito sobre Roscher y Knies puede leerse: «Si en el ámbito de las consideraciones metafísicas puede caber a tales posturas algún sentido y cuál podría ser éste es algo que queda aquí por completo sin resolver, al igual que tampoco cumple tratar de las dificultades reales de la "causalidad por libertad" (Kausalitätdurch Freiheit) y demás construcciones con ella emparentadas, las cuales podrian comenzarse a abordar justamente en el ámbito metafísico. En todo caso, el "psicologismo" -o sea, la pretensión de la psicología de constituir o crear una "visión del mundo" (Weltanschatung) - es un sinsentido $y$, para el libre espiritu de las ciencias empiricas, algo tan peligroso como un "naturalismo" a partir de un fundamento tomado de la mecánica o de la biología o un "historicismo" fundado sobre la "historia de la cultura." (WL, pp. 62-63).

33. Vid. KrV A 444-452; B 472-480 y A 532-558; B 560-586.

34. Cosa crucial para poner en su sitio los frecuentes usos weberianos del término "destino", bajo cl que se agazapan connotaciones muy varias que en ningún caso autorizan a pensar en un Weber adalid del fatalismo histórico. Resulta imprescindible tener en cuenta esta circunstancia para no dejarse despistar por el empleo metafórico de "Schicksal» tan habitual en Weber, según habrá ocașión de comprobar más adelante.

35. Luc Ferry ha desarrollado una sugestiva interpretación de las concepciones de la historia prevalecientes en la Modernidad a partir del modelo de las antinomias de la $\mathrm{KrV}$, de cuya "solución critica" hacc hercdero a Weber. El texto de Weber arriba reproducido constituye una buena confirmación de lo pertinente de la estrategia de Ferry. Cfr. L. Ferry, Philosophie politique. 2 Le systeme des philosophies de l'histoire, París, P.U.F., 1984, pp. 108-138. Vid. sobre la articulación de ética y filosofía de la historia en Kant los trabajos de Roberto Rodríguez Aramayo "El "utopismo ucrónico" de la reflexión kantiana sobre la historia" (estudio preliminar a Inmanuel Kant, Ideas para una historia universal en clave cosmopolita y otros escritos sobre Filosofia de la Historia, traducción de Concha Roldán y Roberto Rodriguez Aramayo, Madrid, Tecnos, 1987, pp. ix-xliv), y "La filosofía de la historia en Kant: una encrucijada de su pensamiento moral y políticom, en Claudio La Rocca y otros, Eticidad y Estado en el idealismo alemán, Valencia, Natán, 1987, pp. 5-17.

36. Si bien, en polémica con Gierke, apunta Weber una interpretación kantiana al señalar que el estatus del "cosmos de ideas y relaciones" expresado por las totalidades comunitarias agentes de la historia no es el de un misterio místico que obligue a crear una ontología especial de la vida histórica, sino, en palabras de Weber, más bien el de suna idea. ética (sittliche Idee) regidora de la voluntad y el sentir de los hombres". Cfr. WL, p. 35, nota 1.

37. Aludiendo a Mandeville y a Goethe, pone en guardia Weber al lector contra los resabios providencialistas de la filosofia ilustrada de la historia (¿también de la kantiana?). Roscher habia invalidado la pretensión de convertir la historia en teodicea y los ensueños schillerianos de un atribunal universal" (aunque su filosofía de la historia tuviera después que colocar un organicismo ingenuo en el lugar dejado vacante por la teleología) y, al hilo del comentario de Roseher, ofrece Weber su reinterpretación de la idea de progreso como 
la secularización de uun destino de la humanidad vaciado de fin religioso». Cfr. $W L$, p. 33. nota 2.

38. Vid. WL, pp. 217-218.

39. 1 lbid.

40. Cfr. p. e., E. Baumgarten, Max Weber, Werk und Person, Tubinga, J.C.B. Mohr (Paul Siebeck), 1964, p. 139.

41. Cfr. WL, p. 63.

42. Expresión, como se sabe, intencionadamente fichteana debida a Marianne Weber.

43. Así fue puesto de manifiesto por el clásico trabajo de Dieter Henrich (esencial para la comprensión de los escritos epistemológicos de Weber) Die Einheit der Wissenschaftslehre Max Webers, Tubinga, J.C.B. Mohr (Paul Siebeck), 1952.

44. Pronunciada el 19 de enero de 1919 (y muy probablemente repetida en marzo de dicho año) por invitación del Freistudertische Bund, organización de estudiantes liberalesmuniqueses, dias antes de dictar la no menos conocida "Politik als Beruf». Sobre la datación y circunstancias de las dos conferencias de Munich, vid. W. Schluchter, "Wertfreiheit und Verantwortungsethik. Zum Verhälnis von Wissenschaft und Politik bei Max Weber ("Exkurs: Zur Frage der Datierung der Vorträge "Wissenschaft als Beruf" und "Politik als Berul"), en su colección de ensayos Rationalismus der Weltbeherrschurg. Studien zu Max Weber, Francfort, Suhrkamp, 1980, pp. 236-239. Citaré la conferencia por la paginación de WL. Existen diversas traducciones castellanas de la conferencia.

45. Cfr. $W L$, p. 589.

46. Clr. WL, p. 591.

47. Puede verse el comentanio de Weber en donde se glosa la opinión de Simmel favorable a conceder a las "personalidades "de vigoroso perfil". "individuales" en el mayor grado* ("scharfumrissene», höchstgradig «individuelle» Persönlichkeiten) el máximo nivel de aptitud para la acomprensión». Corolario de ello era para Simmel la exigencia de que el propio historiador poseyera una "personalidad" parejamente excelente. Cfr. WL, p. 101 . nota 2.

48. La interpretación de la historia del término Enebnis ofrecida por Gadamer (vid. Verdad y método, traducción de Ana Agud y Rafael de Agapito, Salamanca, Sigueme, 1977, pp. 90-101) constituye una excelente documentación de la interrelación entre modelos gnoseológicos y conceptos crítico-culturales en el siglo xTX alemán.

49. Como señala Gadamer, "Goethe puede inducir más que ningún otro a la formación de esta palabra [Erlebnis], porque su poesía es comprensible en un sentido bastante nuevo precisamente a partir de sus vivencias. El mismo [Dichtung und Wahrheit, segunda parte, libro VII, Werke, XXVII, 110] llegó a decir de sí que todos sus poemas revisten el carácter de una gran confesiónn. (CFi. H.-G. Gadamer, op. cit., p. 98). No es gratuito, pues, obscrva Gadamer, que el neologismo decimonónico Erlebnis se incorpore a la lengua usual precisamente en el ámbito de la literatura biografica (p. 97). La inacabada biografia diltheyana de Schleiermacher (1870), la de Winckelmann por Justi (1872) y, sobre todo, el Goethe de Hermann Grimm (1877) constituyen ejemplos característicos, para Gadamer, de ese ideal del centendimiento de la "obra" a partir de la "vida" " que tan netamente ilustra lo que he llamado el modelo historicista de la subjetividad integral.

50. Cfr. WL. p. 592.

51. "En el ámbito de la ciencia, sólo tiene "personalidad" quien sirve pura y simplemente a su cometido (der rein der Sache dienst,» (WL, p. 591).

52. Ibld. En su popular obra (solapadamente weberiana, en su conjunto) The Cultaral Contradictions of Capitatism. Daniel Bell no tuvo mejor ocurrencia para cifrar el designio máximo de la cutura modernista que acudir a máxima tan polisémica como la que prescribe convertir la vida propia en obra artística. El susodicho manifiesto, precursor aventajado de soflamas conservadoras menos ingeniosas, no anda escaso de usos tácitos y nada desinteresados de "Wissenschaft als Beruf*.

53. Cfr, WL, p. 591 . 
54. Jose María González García prepara en la actualidad un apasionante estudio sobre el tema, de cuyas partes ya elaboradas he tenido conocimiento gracias a su amabilidad. En su artículo "La herencia de Kant en el pensamiento de Max Weber» (Vid. Javier Muguerza, Roberto Rodriguez Aramayo (eds.), Kant después de Kant, Madrid, Tecnos-Instituto de Filosofia (CSIC), 1989, pp. 481-499) ha apuntado algunas de las huellas fundamentales de Goethe en Weber, La presencia de Goethe es, en efecto, constante leit motiv, por lo pronto, de «Wissenschaft als Beruf», según habrá ocasión de comprobar.

55. Autor éste accradamente crítico de la subordinación de la historia al ideal biográfico. La crítica de Weber a Meyer constituye la inversión más radical del ideal historicista; para Weber será la biografía la que se resuelva en historiografia causal.

56. E. Meyer, Zur Theorie und Methodik der Geschichte (1902), p. 56 (cit. por Weber, WL, p. 240).

57. La tipología de Weber, cuyo orden expositivo sacrifico aquí en aras de la claridad, se encontrará en WL, pp. 241-245, y es como sigue:

A) Elemento causal de un nexo histórico.

B) Elemento *caracteristico" de un conjunto colectivo.

B.1) Medio de conocimiento de lo caracteristico de la inaividualidad histórica.

B.2) Medio de conocimiento del paradigma de un tipo humano.

C) Ejemplar de an género.

C.1) Medio para la obtención de un concepto genético de género.

c.2) Ejemplo tipico-ideal de fenómenos no culturales.

En el caso $A$, el historiador procura descubrir el modo como las vivencias expresadas en las cartas de Goethe pueden explicar otras partes de su obra, así como su upersonalidad" literaria. De esta forma, los hechos de que nos dan noticia las vivencias de Goethe (en este caso sus estados de ánimo) son miembros reales de una cadena causal. En el caso B.1, pueden deducirse de las cartas rasgos esenciales del uestilo de vida» (Lebensfuhrung) de Goethe, insertando así las "vivencias» expresadas en las cartas en una trama causal dentro de la cual se convierten en "síntoma" o "medio de conocimiento" de elementos característicos de la individualidad llamada Goethe. En B.2 puede buscarse la inserción de las vivencias en una trama causal que culmine en la determinación de un «tipo humanon genérico (p. e, el alemán de la época); las vivencias operan así como «medion para descubrir rasgos característicos de ese tipo humano. En C.1 las vivencias de Goethe nos pueden servir de medio para descubrir -en el supuesto de que no nos desvelen ninguna peculiaridad individual de Goethe o caracteristica de su tiempo o circunstancia-fenómenos que sean comunes a todas las culturas (p. 'e., el ascetismo, cierta concepción del amor). En ese caso, cabe obtener un "concepto de gênero" (Gattungsbegriff) en el que se formule la "regla» que se aplicó mediante la abstracción y la generalización a partir de lo significado por las vivencias. Finalmente, en el caso C.2 (el de menor interés para Weber) un cultivador de disciplinas ajenas a la historia puede descubrir en las vivencias de Goethe rasgos psicopatológicos que configuren un tipo ideal de conducta eróticamente aberrante (al modo como las Confesiones de Rousseau son útiles para el especialista en enfermedades nerviosas).

58. Ibid,

59. Cfr. $W L$, p. 589.

60. Contra Gottl, señalaba ya Weber en «Roscher und Knies» lo absurdo del ideal de comprensión ilimitada de una totalidad de «vivencias»: *No es correcto (...) hacer un inventario de todas las vivencias cotidianas (Aittagserlebmisse) de un día en todos sus elementos, ni sostener que en un tratamiento científico -por muy comprehensivo que llegue a serse puedan integrar absolutamente todas las acciones de cualquier tipo que sean». Cfr. WL, p. 95 , nota $3, \S 3$.

61. Cfr. $W L$, p. 604.

62. Cfr. $W L$, p. 591.

63. Según la expresiva traducción de Francisco Rubio Llorente. Vid. «La ciencia como 
vocación", en $M$. Weber, El politico y el cientifico, introducción de Raymond Aron, traducción de F. Rubio Llorente, Madrid, Alianza, 1967, p. 195. Cfr. WL, p. 591.

64. En el escrito sobre Roscher y Knies, había escrito Weber: «Es menester romper la sorda indiferenciación de la "vivencia" (die dumpfe Ungeschiedenheit des "Erlebens") (...) para dar el primer paso de una real "comprensión" (wirklichen "Verstehens") de nosotros mismos. Cuando se dice que cada "vivencia" (Erlebnis) es lo más cierto de entre lo cierto (das Gewisseste des Gewissen), se quiere señalar con ello, naturalmente, el hecho de que hemos vivido alguna cosa (dass wir erleben). Pero qué cosa sea propiamente la que vivamos (was wir aber eigentlich erleben), esto es algo que a cualquier "interpretacion" (jede "deutende" Interpretation) sólo le es dado alcanzar a condición de abandonar el estadio de la "vivencia" (Enlebens) misma y de convertir lo vivido (das Erlebte) en el "objeto" de un juicio cuyo contenido, por su parte, no se reconocerá como "vivido" en una indiferenciada tiniebla (in ungeschiedener Dumpfheit), sino más bien como "válido" (geltertd)». Cfr. WL, p. 104.

65. "Cuanto más "libre" - en el sentido que le doy- es la "acción", es decir, cuanto menos muestra su carácter de "devenir natural", tanto más crecerá igualmente en vigor al tin aquel concepto de "personalidad" que halla su "esencia" en la constancia de sus relaciones internas con determinados "valores" $\mathrm{y}$ "significados" últimos de la vida, los cuales se acuñan en forma de fines en su actuar (die sich in ihrem Tun zu Zwecken ausmünzen) y así lo transforman en una acción teleológico racional (teleologisch-rationales Handeln).» Cfr. $W L$, p. 132.

66. Cfr. WL, p. 604.

67. Ibid.

68. Cfr. M. Weber, Economía y sociedad, traducción de J. Medina Echavarria et alii, México, F.C.E., 1984, pp. 193 ss.

69. «Todas ellas [la libertad de conciencia, la inviolabilidad de la propiedad, la libertad contractual, la libre elección de profesión] encuentran su última justificación en la creencia propia de la época de la Ilustración, según la cual la "razón" del individuo, siempre que se le conceda vía libre, conducirá al mejor mundo posible en virtud de la Divina Providencia y a causa de que el individuo es el que mejor conoce sus propios intereses. La glorificación carismática de la "Razón" (que encontró su expresión caractcrística en la apoteosis de Robespierre) es la última forma que ha adoptado el carisma dentro de sus multiples posibjlidades." Cfr. Max Weber, Economia y sociedad, cil., p. 937.

70. Una muy sugestiva reflexión sobre el particular se hallará en José L. Villacañas, "Razón y Beruf: el problema de la eticidad en Kant y Weber", en J. Muguerza, R. Rodríguez Aramayo (eds.), Kant después de Kant, cit., pp. 501-529. Guenther Roth se ha servido de este concepto para un excelente análisis de algunas formas contemporáneas del carisma en "Charisma and Counterculture" (vid. G. Roth, W. Schluchter (eds.), Max Weber's Vision of History: Ethics and Methods, Berkeley, University of California Press, 1979, pp. 119-143).

71. Parece documentado el aprecio de Weber por Schiller, al que en algunos aspectos considera moralmente superior a Goethe, si bien eclipsado por la fama de éste. En una carta de juventud a su prima hermana Emmy Baumgarten - de la que estaba enamoradose expresa ya esta preferencia. Vid. Eduard Baumgarten, Max Weber, Werk und Person, op. cit., p. 627.

72. Friedrich Schiller, wUeber Anmut und Würdex, Philosophische Schriften, hrsg. von Albert Köster, Leipzig. Insel Verlag, s.f., p. 39. Reproduzco la traducción castellana Sobre la gracia y la dignidad. Sobre poesía ingenua y poesta sentimental Y tna polémica Kant-Schiller-Goethe-Hegel, traducción de Juan Probst y Raimundo Lida, revisada por el Instituto de Literaturas Anglo-germánicas de la Universidad de Buenos Aires, Barcelona, Icaria, 1985, p. 45.

73. «Es, pues, en cl alma bella donde armonizan la sensibilidad y la razón, la inclinación y el deber, y la gracia (Grazie) es su expresión en lo fenoménico. Sólo al servicio de un alma bella puede la naturaleza poseer la libertad y al mismo tiempo conservar su forma, ya que pierde lo uno bajo la dominación de un ánimo severo y lo otro bajo la anarquía de la 
sensorialidad. Un alma bella derrama gracia irresistible (eine unwiderstehliche Grazie) aun sobre una forma que carezca de belleza arquitectónica, y a menudo la vemos triunfar hasta de los defectos de la naturaleza." (Friedrich Schiller, "Ueber Anmut und Würdes, philosophische Schriften, p. 278 (trad. cast. pp. 45-46).

74. En su trabajo "Los sentimientos del alma bella: Schiller, Goethe, Hegel» (ponencia presentada a la VI Semana española de Etica y Filosofia Política, Oviedo, marzo 1990), Jose M. González García ha mostrado los rasgos de la aparición del tema del alma bella en los Lehrjahre del Meister, señalando sus ecos weberianos en las páginas finales de La ética protestante. La "humanidad integral y bella" (volte tund schöne Menschentum) es, en efecto, la común renuncia de Goethe y Weber.

75. La exposición de los conceptos de sdominación carismática» y de srutinización del carisma» se hallará en la "Teorfa de las categorias sociologicas" de Economía y sociedad (pp. 193-203 de la edición castellana) y su desarrollo más detallado en la "Sociología de la dominación» de la misma obra (pp. 847-889 de dicha edición).

76. Vid. M. Weber, Gesammelte politische Schriften, dritte, erneut vermehrte Auflage, mit einem Geleitwort von Theodor Heuss, hrsg. von Johannes Winckelmann, Tubinga, I.C.B. Mohr (Paul Siebeck), 1971, p. 282.

77. Cfr. WL, p. 603.

78. Consccuencia de la separación de esferas de valor es la imposibilidad de un modo de conocimiento integrado del sujeto humano en su conjunto. Contra Münsterberg, impugna Weber la contraposición entre una psicología ucientífica" y una psicología ade conocedor de hombres» (Menschenkenners) (en un sentido esta última que no deja de recordar al nietzscheano), y asi, respecto de su frase ${ }^{\mathrm{E}} \mathrm{El}$ conocedor de seres humanos conoce al ser humano entero (den ganzen Menschen) o no lo conoce en absolutow, responde que lo que en verdad conoce tal «psicólogo" es «aquello que del ser humano es relevante para determinados fines concretos, $\mathrm{y}$, de lo contrario, nada en absoluton. Cfr. $W L$, p. 81, nota 1 . El fraccionamiento de los valores - a cada uno de los cuales irán asociados fines igualmente incomposibles- implica que el sujeto sólo sea cognoscible en su relación con las finalidades de una investigación parcial.

79. Cfr. WL., pp. 603-604. No puedo entrar aquí en el espinoso asunto de las relaciones Nietzsche-Weber, objeto de amplia tradición hermenéutica. Vid. la relación bibliográfica proporcionada por J.M. González Garcia, op. cit., p. 483, nota 3, a la que puede anadirse Ralph Schroeder, "Nietzsche and Weber: Two "Prophets" of the Modern World", en Scott Lash, Sam Whimster (eds.), Max Weber, Rationality and Modemity, cit., pp. 207-221.

80. Sobre las metamorfosis del carisma en las sociedades contemporáneas puede verse Salvador Giner y Manuel Pérez Yruela, «La manufactura del carisma», en Carlos Castilla del Pino (ed.), Teoría del personaje, Madrid, Alianza, 1989.

81. Cfr. WL, p. 589.

82. El exhaustivo estudio de Wolfgang Schluchter constituye la mejor exposición del problema y es, en sí mismo, la más idónea receta contra cualquier simplificación. Vid. W. Schluchter, Religion und Lebensführong. Bd. 1. Studien ztu Max Webers Kultur und Werttheorie, Francfort, Suhrkamp, 1988, cap. 3 ("Gesinnungsethik und Verantwortungsethik. Probleme einer Unterscheidungn), pp. 165-338. Terminado ya de redactar este trabajo, tuve ocasión de leer con interés el nada simplificador artículo de Francisco I. Laporta «Ética y política. Algunas claves básicas» (Claves de razón práctica, 2, mayo 1990; pp. 15-21), agudo alegato en favor de la Gesinnungsethik que muestra los flancos menos fuertes de la ética de la responsabilidad al ser sometida a la prueba de los efectos no intencionados de la acción.

83. No es extraño que el diagnóstico weberiano sirva de patrón a otras lecturas contemporáneas de la crisis de la racionalidad práctica ilustrada en las que, además de renunciarse al "carisma de la razón», se viene a propugnar la liquidación por derribo de esta última (no sin apelar, por cierto, a carismas aún más rutinizados). Así, MacIntyre ha podido definir peyorativamente nuestra época como una era weberianas (vid. su Afler Vintue. A Siudy in Moral Theory, 2nd edition, Notre Dame (Indiana), University of Notre Dame 
Press, 1984, pp. 109 ss.). Junto a más de una observación sin la que el presente artículo no habría llegado a escribirse, debo a Helena Béjar (ni en éste ni en níngún otro punto habrá el lector de pasarle a ella la cuenta de mis desatinos) haberme llamado la atención sobre las consecuencias del nada trivial - aunque sí falaz-paralelismo entre la lesis weberiana del "politeísmo de los valores" y lo que Macintyre ha designado como "contenido social del emotivismo". Que al "emotivismo" contra el que argumenta Macintyre le convendría mejor la etiqueta de «moral psicologista» creo que es algo en lo que no me queda más remedio que dar la razón a Helena Béjar, como habrả de hacerlo sin duda quien, para mejor entendimiento de la casa de juegos en que andamos, lea su artículo "La virtud del deseo" ( $E l$ Pais, 12 abril 1989). Sobre el equívoco concepto de ucultura moral emotivistas en After Virtue, puede verse con provecho: Richard $\mathbf{E}$. Flathman, "Culture, Morality and Rights: Or, Should Alasdair MacIntyre's Philosophical Driving License Be Suspended?», Analyse und Kritik, 6 (1984), pp. 8-27.

84. No puedo entrar aquí en la discusión sobre el problema del adecisionistno" de Max Weber, aunque no es ocioso señalar cómo algunas de sus críticas más abruptas (la de Habermas es conocida; cfr. su escrito de 1964 «Neutralidad valorativa y objetividad» en La lógica de las Ciencias sociales, traducción de M. Jiménez Redondo, Madrid, Tecnos, 1988, p. 71-77) presuponen un cognoscitivismo disimulado o expreso contra el que la lectura de Weber puede resultar hoy harto saludable. Dos buenas aproximaciones a la cuestión son: Nora Rabotnikof, "Racionalidad y decisión política en Max Weber", en León Olivé (ed.), Racionalidad. Ensayos sobre la racionalidad en ética y politica, ciencia y tecnología, cit., pp. 99-110, y Stephen Tumer, Regis Factor, «Decisionism and Politics: Weber as Constitutional Theorist, en Scott Lash, Sam Whimster (eds.), Max Weber, Rationality and Modernity, cit, pp. 334-354. La relación entre Carl Schmitt y Max Weber, con frecuencia esgrimida como argumento ad hominem contra el segundo, ha sido estudiada entre nosotros por Germán Gómez Orfanel (víd. su Excepción y nomalidad en el pensamiento de Carl Schmitt, Madrid, Centro de Estudios Constitucionales, 1986, pp. 89-102).

85. WL, p. 609 .

86. Ibid.

87. WL, p. 613. La expresión es de Goethe (aforismos 2 y 3 de las Betrachtungen im Sinne der Wanderer. Vid. Jose M. González Garcia, op. cit., p. 500.).

88. Cfr. sobre todo aDie "Objektivität" sozialwissenschaft licher und sozialpolitischer Erkenntnis" (WL, pp. 146-214) y "Der Sinn der "Wertfreiheit" der soziologischen und ökonomischen Wissenschaften» (WL, pp. 489-540). Salvador Giner ha mostrado con exactitud la distinción entre el ideal de neutralidad valorativa de la ciencia social y el «desinterés cínico acerca de las intenciones humanas en el proceso de investigación o acerca de las consecuencias morales cognoscibles o probables de sus descubrimientos». La confusión entre to primero y lo segundo constituye lo que Giner llama «Falacia de la Objetividad Amoral". Vid. S. Giner, "Sociología y filosofía moral», en Victoria Camps (ed.), Historia de la ética. 3. La ética contemporanea, Barcelona, Crítica, 1989, pp. 118-162. Cfr. especialmente pp. 118-121 y, en lo tocante a Weber, 132-137.

89. Es interesante notar que, para Weber, la figura del científico contemporáneo no puede entenderse en términos distintos de los de funcionario público (rotra rutinización del carisma del intelectual integral?; recuérdese que los recursos del jefe carismático en la "sociología de la dominación» eran los provistos por una economía basada en la donación y el mecenazgo).

90. ¿Por qué no a la opinión pública? ¿Permanece el kantiano Weber presa de la distinción entre "uso público» y «uso privado de la razón»?

91. En un ensayo reciente, Agnes Heller ha señalado cómo la elección misma de lo que Weber llama "hechos incómodos» se halla presidida por la lógica de la valoración: "Cuando Weber insiste en que los científicos sociales deben hacer siempre un inventario de los llamados "hechos desagradables" (los que cuestionan o socavan sus teorias), estableció un buen argumento contra la retórica fuerte, pero no contra la evaluación como creyó 
haber hecho. Esto se debe simplemente a que los hechos no son inherentemente agradables o desagradables, sino que se vuelven agradables o desagradables desde el punto de vista (...) del valor que guía una teoria concreta. El mismo hecho puede resultar extremadamente molesto para un cientifico social y ser providencial para otron. (CFr. A. Heller, "De la hermenéutica en las ciencias sociales a la hermenéutica de las ciencias sociales", en A. Heller, F. Fehér, Politicas de la postmodernidad. Ensayos de critica cultural, traducción de Montserrat Gurguí, Barcelona, Península, 1989, pp. 63-64). Por mi parte, no creo que se trate de un "argumento" en favor de la neutralidad valorativa, sino más bien de una sexigencià de la misraa. Weber no se refiere a los hechos que resultan incómodos para el mantenimiento de la teoría (no es un popperiano avant la lettre), sino a los que resultan desagradables para la escala de valores prevaleciente en el ámbito de recepción de la misma. En rigor, lo que està definiendo Weber es el estatus del clentifico - del docente, en concreto- como agente del debate moral, y no la manera como la valoración afecta al contenido de las teorías (que él propugna ha de ser irrelevante). Que los hechos son agradables o desagradables en virtud de estimaciones de valor es cosa que va de suyo, y en ningún caso Weber ha insinuado I contrario.

92. Cfr. WL, p. 608.

93. F. Schiller, op. cit, p. 52 (traducción castellana, pp. 284-285).

94. Términos que Weber cita de la obra de Gottl Die Herrschaft des Wortes (cfr. WL, p. 98),

95. Heredera insatisfecha de Kant, no sé si al alma sublime de Schiller le convienen por entero las criticas que la hermenéutica feminista contemporánea ha dirigido al contenido sexista del sentimiento de lo sublime kantiano. Concha Roldán ha mostrado con rigor las incoherencias del proyecto universalista ilustrado que este último manifiesta, y no es seguro que Schiller, a pesar de que identifique la gracia con el género femenino y deje prudentemente asexuada la dignidad, esté libre de una interpretación que desenmascare fisuras semejantes a las que cuartean la filosofia práctica kantiana. Cfr. Concha Roldán, "Las Observaciones sobre el sentimiento de lo bello y lo sublime. ¿Una fisura en la pretensión de universalidad de la ética kantiana?", ms. inédito (comunicaciốn presentada a la VI Semana española de Ética y Filosofía Política, Oviedo, marzo 1990).

96. Son conocidas las protestas de Adorno contra este engullimiento de lo natural por el concepto de dignidad: al cicatrizar la «herida» de la belleza natural, para el sujeto autónomo constituido en la afirmación de su propia dignidad sla verdad de tal libertad (...) es su falta de verdad: falta de libertad para lo distintos (Theodor W. Adorno, Teoria estética, traducción de Fernando Riaza, Madrid, Taurus, 1971, p. 88), y su efecto más seralado no es otro que ala muerte de cuanto no esté totalmente dominado por el sujeton (ibid.). En último tếrmino, el concepto de una dignidad producida por la renuncia de la gracia prueba su naturaleza espuria: «los hombres no están dotados positivamente de dignidad, sino que ésta es tan sólo lo que todavia no son* (ibid.), mientras que la hipóstasis schillenana "se desvelaría como usurpación del sujeto que degrada todo cuanto no le esté sometido y convierte las cualidades en meros materiales» (ibid.). La belleza natural, «huella que deja lo no idéntico en las cosas presididas por la dura ley de la absoluta identidadn (op. cit., p. 101) constituía la "promesa de una nostalgias (ibid.), y, tras de su aniquilación por el sujeto idealista, resulta ser "toda la cifra de lo que aún no existe, de lo posible». (op. cit., p. 102). Creo que Adorno da en ei clavo cuando señala el objeto de la pérdida (y su nostalgia es de la misma estirpe que la que vemos en Weber), si bien el designio de su recuperación se halla sometido a las aporías de un concepto de naturaleza ya difícilmente pensable.

97. A Victoria Camps se debe una inteligente reivindicación contemporánea de la dignidad, a la que engarza en el schönes moralischen Ganze de la kantiana Metafisica de las costumbres. Cfr. su trabajo \&La dignidad según Kant», en M. Cruz, M.A. Granada, A. Papiol (eds.), Hisioria, lengucije, sociedad. Homenaje a Emilio Lledó, cit., pp. 416-424. Para $V$. Camps, el lugar de la dignidad no está tanto entre wlas normas de la vida justa" cuanto en la unagotable patdeia moral» exigida por el primero de los "deberes para con uno 
mismon de los Principios metafísicos de la doctrina de la virtud. Más bien que virtudes como las especificadas por Kant, el ideal de una personalidad moral y digna solicitaria «unas actitudes, unos atributos o disposiciones que identificaran al buen ciudadano o a la buena persona». Que la paideia moral moderna sea por principio inagotable constituye - piensoun buen indicio de que la atotalidad moral bellas no puede valer como atributo de sujeto empírico alguno imaginable. Sobre la radical independencia del sujeto moral respecto del empirico (única forma de hablar con sentido del primero), me atengo a lo defendido por Javier Muguerza (vid. su Tanner Lecture sLa alternativa del disenso", en Gregorio Peces-Barba (ed.), El fundamento de los derechos humanos, pp. 49-50). Mientras que la gracia no parece que pueda ser exigible al sujeto moral (y que lo sea al empírico parece reñido con el carácter gratuito de aquélla), acaso no suceda lo mismo con la dignidad, sobre cuya aptitud para configurar totalidades bellas no conviene, por lo demás, albergar ilusiones excesivas. Un excelente estudio de la obra de Schiller como respuesta a la filosofía moral y a la estética de Kant es el de R.D. Miller, Schiller ard the Ideal of Freedom, prólogo de Isaian Berlin, Oxford, Clarendon Press, 1970. 